\title{
Computational Analysis of the G-III Laminar Flow Glove
}

\author{
Mujeeb Malik ${ }^{1}$ \\ Computational AeroSciences Branch, NASA Langley Research Center, Hampton, VA 23681 \\ Wei Liao ${ }^{2}$ \\ National Institute of Aerospace, Hampton, VA 23666 \\ Elizabeth Lee-Rausch ${ }^{3}$, Fei $\mathrm{Li}^{4}$, Meelan Choudhari ${ }^{5}$ and Chau-Lyan Chang ${ }^{6}$ \\ Computational AeroSciences Branch, NASA Langley Research Center, Hampton, VA 23681
}

\begin{abstract}
Under NASA's Environmentally Responsible Aviation Project, flight experiments are planned with the primary objective of demonstrating the Discrete Roughness Elements (DRE) technology for passive laminar flow control at chord Reynolds numbers relevant to transport aircraft. In this paper, we present a preliminary computational assessment of the Gulfstream-III (G-III) aircraft wing-glove designed to attain natural laminar flow for the leading-edge sweep angle of $34.6^{\circ}$. Analysis for a flight Mach number of 0.75 shows that it should be possible to achieve natural laminar flow for twice the transition Reynolds number ever achieved at this sweep angle. However, the wing-glove needs to be redesigned to effectively demonstrate passive laminar flow control using DREs. As a by-product of the computational assessment, effect of surface curvature on stationary crossflow disturbances is found to be strongly stabilizing for the current design, and it is suggested that convex surface curvature could be used as a control parameter for natural laminar flow design, provided transition occurs via stationary crossflow disturbances.
\end{abstract}

$\begin{array}{lll}C & = & \text { wing/airfoil chord length } \\ C_{\mathrm{L}} & = & \text { lift coefficient } \\ C_{p} & = & \text { pressure coefficient } \\ c_{\mathrm{r}} & = & \text { disturbance phase speed } \\ f & = & \text { disturbance frequency } \\ H & = & \text { flight altitude } \\ M & = & \text { free stream Mach number } \\ \mathrm{N} & = & \text { N-factor } \\ \mathrm{Re}_{\mathrm{c}} & = & \text { Reynolds number based on wing chord } \\ \mathrm{Re}_{\theta} & = & \text { Reynolds number based on boundary layer momentum thickness } \\ s & = & \text { surface distance } \\ \mathrm{T}_{\mathrm{adb}} & = & \text { adiabatic wall temperature } \\ T u & = & \text { turbulence level } \\ \mathrm{T}_{\mathrm{w}} & = & \text { wall temperature } \\ X, x & = & \text { chordwise coordinate } \\ y & = & \text { spanwise coordinate } \\ \kappa & = & \text { surface curvature } \\ \sigma & = & \text { growth rate of disturbance } \\ \theta & = & \text { boundary layer momentum thickness } \\ \lambda & = & \text { spanwise wavelength } \\ \Lambda & = & \text { wing sweep angle } \\ \psi & = & \text { disturbance wave angle }\end{array}$

\footnotetext{
${ }^{1}$ Senior Aerodynamicist, MS 128, Mujeeb.R.Malik@nasa.gov; Fellow, AIAA.

${ }^{2}$ Research Scientist, Wliao@nianet.org; Senior Member, AIAA.

${ }^{3}$ Aerospace Technologist, MS 128, E.Lee-Rausch@nasa.gov; Senior Member, AIAA.

${ }^{4}$ Aerospace Technologist. MS 128, Fei.Li@nasa.gov.

${ }^{5}$ Aerospace Technologist, MS 128, Meelan.M.Choudhari@nasa.gov; Associate Fellow, AIAA

${ }^{6}$ Aerospace Technologist, MS 128, Chau-Lyan.Chang@nasa.gov; Senior Member, AIAA.
} 


\section{Introduction}

Kin friction constitutes about 50 percent of the drag budget of a business jet or a long haul transport aircraft, ${ }^{1-3}$ $S_{\text {as depicted in Fig. 1. Therefore, reduction in skin friction has the potential of yielding substantial savings in fuel }}$ burn. According to a system study, ${ }^{3} 10$ percent reduction in skin-friction drag would result in about 9 percent fuel savings for a $4000 \mathrm{~nm}$ transport aircraft. Since laminar skin friction is much less than the turbulent value, the subject of maintaining laminar flow for high Reynolds number flows (i.e., delay of boundary-layer transition) has been of interest for well over half a century; see Refs. ${ }^{4-8}$ for reviews of the subject.

In low disturbance environments, Tollmien-Schlichting (TS) instability is responsible for transition in twodimensional (2D) boundary layers that can be controlled by favorable pressure gradients, wall suction and wall heat transfer (cooling in air; heating in water). In three-dimensional (3D) swept-wing boundary layers, crossflow instability dominates the transition process, which often manifests itself in the form of stationary corotating streamwise vortices that originate at minute roughness sites $^{9}$; and these vortices breakdown via a high frequency secondary instability mechanism. ${ }^{10-14}$ Crossflow instability can be controlled by using wall suction and there have been a number of experimental campaigns where laminar flow control (LFC) using suction has been demonstrated in subsonic ${ }^{15-17}$ as well as in supersonic ${ }^{18}$ flight.

A three-dimensional boundary layer is subject to crossflow instability owing to an inflection point in the crossflow velocity component (i.e., the component in the direction normal to the inviscid streamlines). Minimizing this velocity component would weaken crossflow instability and yield extended runs of laminar flow. For a given leading-edge sweep angle and unit Reynolds number, the only way to reduce the crossflow velocity component is to minimize the pressure-gradient but that would bring TS instability into play. Thus, swept-wing Natural Laminar Flow (NLF) design is based upon striking a delicate balance by tailoring the pressure distribution such that the crossflow instability is reduced sufficiently while keeping TS growth at subcritical levels with respect to transition. One can only maintain this balance for a limited range of chord Reynolds numbers and LFC via suction must be employed if laminar flow is desired at high Reynolds numbers associated with large transport aircraft.

The wavelength of crossflow disturbances scales with the boundary-layer thickness, with small wavelength disturbances growing first (i.e., at small distance from the wing leading-edge) followed by decay downstream. The longer wave length disturbances become unstable later but remain unstable over longer streamwise distances and eventually breakdown via secondary instabilities that lead to laminar-turbulent transition. Saric et al. ${ }^{19}$ discovered that forcing small wavelength disturbances (i.e., the "control" mode) at relatively high amplitudes changes the boundary-layer mean flow such that the growth of more dominant larger wave length disturbances (i.e., the "target" mode) is pushed downstream, thus delaying transition. This concept has been studied by using nonlinear Parabolized Stability Equations (PSE) ${ }^{20}$ and Direct Numerical Simulations (DNS) ${ }^{21}$ and both these analyses support the soundness of the fundamental concept. In practice, the control mode is introduced via discrete spanwise periodic roughness elements placed near the neutral point of the instability diagram. These control disturbances only introduce harmonics and no subharmonics, and therefore do not directly feed into the larger wavelength target modes. This strategy for controlling crossflow disturbances is known as Discrete Roughness Elements (DRE) technology and it has the potential of increasing the range of applicability of NLF to higher chord Reynolds numbers.

Saric et al. ${ }^{22-23}$ reported a flight experiment using Cessna O-2 aircraft to demonstrate the DRE concept. The test article consisted of a $30^{\circ}$ swept blade that was mounted vertically under one of the wings of the aircraft. Maximum transition Reynolds number obtained on the test article was about 6.4 million when the leading edge was polished with surface finish quoted as $0.3 \mu \mathrm{m}$ root mean square (rms) and $2.2 \mu \mathrm{m}$ average peak-to-peak. Here, transition Reynolds number was limited by pressure minimum (i.e., adverse pressure gradient) because of the relatively low chord Reynolds number of 8 million. In other words, increased extent of NLF could be had for a larger test article. When the leading edge was painted to yield a deteriorated surface finish (quoted as $1 \mu \mathrm{m} \mathrm{rms}$, with $3.8 \mu \mathrm{m}$ peak-topeak), transition Reynolds number dropped to about 2.4 million owing to the adverse effect of surface roughness on transition; with the application of DRE, transition Reynolds number increased to about 4.8 million for the chord Reynolds number of 8 million. This is the highest Reynolds number at which DRE technology has been demonstrated to delay crossflow-induced transition. Clearly, natural laminar flow could be maintained at such Reynolds numbers without the use of DRE and there is need to demonstrate the technology at higher chord Reynolds numbers, Mach numbers and lift-coefficients of relevance to transport aircraft. 
NASA's Environmentally Responsible Aviation (ERA) Project has selected DRE as one of the laminar flow control technologies for further evaluation and development for potential application to transport aircraft. A collaborative effort between Dryden Flight Research Center, Langley Research Center and Texas A\&M University (TAMU) has been initiated whereby flight tests are being planned to increase the transition Reynolds number based on NLF as much as reasonably possible and then increase that Reynolds number even further with the use of DRE. An additional objective of the experiment is to relax the surface finish requirements for swept-wing NLF using DRE as suggested by the results of Ref 23 .

The aircraft selected for the flight experiments is Dryden's Gulfstream-III (G-III, hereinafter G-3) aircraft for which a wing glove has been designed by TAMU. ${ }^{24}$ The glove leading-edge sweep is $34.6^{\circ}$ with a maximum possible chord Reynolds number approaching $30 \times 10^{6}$. The results in this paper provide a computational assessment of the glove using the unstructured-grid Navier-Stokes code, FUN3D ${ }^{25}$ and stability analysis code, LASTRAC. ${ }^{26}$ Based on computational analyses performed at Langley and TAMU, the wing-glove is being redesigned, but the results reported herein use the glove geometry that is currently available.

In this paper, we first describe the objectives of the DRE Laminar Flow Glove Experiment (DRE LFGE), also known as Subsonic Aircraft Roughness Glove Experiment (SARGE), in the context of previous NLF experiments. We then briefly describe the computational tools and present the results obtained to-date, while pointing out that the present analysis is only a snapshot of an ongoing effort as the glove geometry will change before it is manufactured and installed on the aircraft. The role of surface curvature in crossflow-induced transition is also studied.

\section{Research Background}

\section{A. SARGE Objectives}

The goal set by the Environmentally Responsible Aviation Project is to demonstrate Discrete Roughness Elements technology for leading-edge sweep in excess of $30^{\circ}$ and chord Reynolds numbers that are characteristics of mid-range transport aircraft, i.e., $\operatorname{Re}_{\mathrm{c}}$ up to $30 \times 10^{6}$. The Mach number range of interest is 0.66 to 0.75 , with cruise section $\mathrm{C}_{\mathrm{L}}$ of approximately 0.5. NASA Dryden's Gulfstream-III (G-3) aircraft was selected for the Discrete Roughness Elements Laminar Flow Glove Experiment (DRE LFGE), also known as the Subsonic Aircraft Roughness Glove Experiment (SARGE). The G-3 aircraft has a wing leading-edge sweep of $31.7^{\circ}$. The objectives of the planned flight tests are:

- Demonstrate NLF for glove $\mathrm{Re}_{\mathrm{c}}>15 \times 10^{6}$, with laminar flow up to $(\mathrm{x} / \mathrm{c})_{\mathrm{tr}}=0.6$. Therefore, the minimum required transition Reynolds number on the suction side of the glove is 9 million for the prescribed sweep angle.

- Demonstrate effectiveness of DRE in delaying transition by at least $50 \%$ at $\operatorname{Re}_{c}>22 \times 10^{6}$. This means that if natural transition for a given surface finish occurs at $(\mathrm{x} / \mathrm{c})_{\mathrm{tr}}=0.4$, DRE will delay it to $(\mathrm{x} / \mathrm{c})_{\mathrm{tr}}=0.6$.

- Perform experiments with polished and painted leading-edges to demonstrate the effectiveness of DRE in relaxing surface quality requirements for NLF at high Reynolds numbers.

Two rows of pressure ports will be provided to measure surface pressure and thermocouples will be used to measure wall temperature. Transition location on the suction side will be inferred by using an Infra-Red camera and hot films. Laminar flow extent will be measured on the pressure side by using thermocouples, but maximizing laminar flow on this side is not one of the primary objectives of the experiment. The experiment should also yield valuable data for the validation of computational tools.

\section{B. Previous NLF Experiments:}

Several Natural Laminar Flow (NLF) experiments have been conducted over the years in wind tunnels and during flight experiments; and some of the results are presented in Fig. 2 where maximum transition Reynolds numbers are plotted as a function of the sweep angle. Here, transition Reynolds number is based on free stream conditions, rather than local conditions. Most of the data points are taken from Ref. 27 and plotted here for comparison with the intended range of the planned G-3 flight experiment. These include results from the B-18 flight test, ${ }^{28}$ King Kobra flight test, ${ }^{29}$ the Boeing 757 NLF glove, ${ }^{30}$ F-111/TACT NLF glove flight experiment, ${ }^{31}$ F-14 variable sweep transition flight experiment, ${ }^{32}$ low-speed experiments conducted in the Ames 12-Foot Tunnel, ${ }^{33}$ and Langley Transonic Pressure Tunnel (TPT) ${ }^{34}$ More recent sets of data include the White-Knight experiment ${ }^{35}$ 
conducted by Northrop-Grumman and the Cessna O-2 flight experiment referred to above. Both these experiments were conducted on $30^{\circ}$ swept blades installed under the aircraft.

Largest values of transition Reynolds number were obtained for the F-14 flight experiment, where "... a maximum transition Reynolds numbers of about 17.6 million was obtained at 15 degrees of sweep, 13.5 million at 20 degrees, and 12 million at 25 degrees. Beyond 25 degrees of sweep, maximum transition Reynolds number decreased rapidly to about 5 million at 35 degrees of sweep". ${ }^{27}$ It was noted that maximum transition Reynolds numbers were limited by either adverse pressure gradients (i.e., TS dominated transition) or shock wave location. Thus, for a larger wing chord Reynolds number, it should be possible to obtain even higher values of crossflowinduced transition Reynolds numbers for an NLF wing. .

Transition Reynolds numbers for flight experiments conducted in Europe (e.g., ATTAS ${ }^{36}$ and F-100 Fokker ${ }^{37}$ ) are not available in the open literature. However, Ref. 37 notes that in the latter experimental campaign it was possible to achieve laminar flow for Reynolds numbers up to 25 million, for leading edge sweep angles below $23^{\circ}$. It is reasonable to assume that the highest value of transition Reynolds number of $25 \times 10^{6}$ was associated with the lowest sweep angle of $17^{\circ}$ for the F-100 experiment. This is to be compared with the corresponding value of about $16 \times 10^{6}$ for the F-14 experiment. If the above inference from Ref. 37 is correct, the highest reported transition Reynolds number achieved in an NLF flight experiment is from the F-100 Fokker experiment. However, the authors have not been able to confirm this with the principals involved in the experiments.

Transition Reynolds number decreases with increasing sweep angle due to the destabilizing effect of crossflow. Data points from two recently conducted flight experiments (White-Knight ${ }^{35}$ and Cessna O-2 ${ }^{23}$ ) have also been included in Fig. 2. The test article in the White-Knight experiment also included a $30^{\circ}$ swept blade attached to the aircraft. Maximum transition Reynolds number obtained in this case was about $5.6 \times 10^{6}$ and was limited by the pressure minimum (i.e., adverse pressure gradient) because of the relatively low chord Reynolds number of $7.1 \times 10^{6}$. Results from the Cessna O-2 have been discussed before. The expected range of transition Reynolds number of the SARGE is also shown in Fig. 2, where the lower bound comes from the NLF requirement and the upper bound is derived from the maximum Reynolds number attainable for the G-3 glove under the assumption that laminar flow can be achieved up to $60 \%$ chord using DRE. The minimum expected Reynolds number of $9 \times 10^{6}$ is $80 \%$ higher than that achieved in the F-14 flight experiment at this sweep angle of about 35 degrees.

\section{Glove Design}

Glove design was carried out by Texas A\&M University and is discussed in Ref. 24. The glove as installed on the G-3 aircraft wing is shown in Fig. 3(a-b). It has a leading-edge sweep of $34.6^{\circ}$, is $6 \mathrm{ft}$ wide and has a streamwise chord length of $14.5 \mathrm{ft}$. The glove is smoothly faired into the wing on inboard, outboard and downstream sides. With wing-glove thickness $(t / c)$ and section-lift coefficient $\left(\mathrm{C}_{\mathrm{L}}\right)$ as constraints, design proceeded to place the pressure minimum as far aft as possible so that the boundary-layer is subcritical to TS-induced transition. Linear stability results were used to guide the design for crossflow control. The leading-edge radius was limited by the requirement that $\operatorname{Re}_{\theta}<100$ to assure that the attachment-line boundary layer is subcritical to any spanwise contamination, although this requirement could have been relaxed owing to the inboard leading-edge fairing that would act as a Gaster bump. The requirement for clearance between the glove and the wing resulted in a thicker and longer glove (see Fig. 3(c)) than it might have been otherwise. However, this inadvertently made the design more interesting from the view point of the effect of surface curvature, which we will address towards the end of the paper.

\section{Computational Tools}

\section{A. FUN3D}

FUN3D ${ }^{25,38}$ is a finite-volume Navier-Stokes solver in which the flow variables are stored at the vertices or nodes of the mesh. FUN3D solves the equations on mixed element grids, including tetrahedra, pyramids, prisms, and hexahedra and also has a two-dimensional path for triangular/quadrilateral grids. At interfaces delimiting neighboring control volumes, the inviscid fluxes are computed using an approximate Riemann solver based on the values on either side of the interface. Several convective flux schemes are available in FUN3D. The most common scheme for subsonic and transonic flows is Roe's flux difference splitting, ${ }^{39}$ which is used in the current study. For second-order accuracy, interface values are obtained by extrapolation of the control volume centroidal values, based on gradients computed at the mesh vertices using an unweighted least-squares technique.

For tetrahedral meshes, the full viscous fluxes are discretized using a finite-volume formulation in which the 
required velocity gradients on the dual faces are computed using the Green-Gauss theorem. On tetrahedral meshes this is equivalent to a Galerkin type approximation. For non-tetrahedral meshes, the same Green-Gauss approach can lead to odd-even decoupling. A pure edge-based approach can be used to circumvent the odd-even decoupling issue, but yields only approximate viscous terms. Thus for non-tetrahedral meshes, the edge-based gradients are combined with Green-Gauss gradients, which improves the h-ellipticity of the operator, and allows the complete viscous stresses to be evaluated. ${ }^{40}$ This formulation results in a discretization of the full Navier-Stokes equations.

The solution at each time-step is updated with a backwards Euler time-integration scheme. At each time step, the linear system of equations is approximately solved with either a multi-color point-implicit procedure or an implicitline relaxation scheme. ${ }^{38}$ Local time-step scaling is employed to accelerate convergence to steady state. For turbulent flows, several models are available within FUN3D, including the loosely coupled Spalart-Allmaras (S-A) model. ${ }^{41}$

\section{B. Unstructured Grid}

The unstructured-grid tool VGRID ${ }^{42}$ was employed to generate a tetrahedral grid for the G-3 configuration with the glove. Only one-half of the aircraft was gridded as flow symmetry was assumed along the centerline of the fuselage. Since the region of particular interest for this study is the mid-span region of the wing, the tail was not simulated and some minor details of the engine nacelle geometry were ignored. Powered engine conditions as provided by Ref. 43 were used for computation of the aircraft flowfield. A mixed-element grid consisting of tetrahedrons and prisms was used in the viscous flow computations, where the prisms were generated by recombining the tetrahedral grid in the advancing layers.

\section{LASTRAC}

Stability calculations have been performed by the Langley Stability and Transition Analysis Code, LASTRAC. ${ }^{26}$ The LASTRAC software is a suite of general purpose, stability and transition analysis tools that encompass a broad range of the state-of-the-art numerical methods based on linear stability theory (LST), linear and nonlinear parabolized stability equations (PSE), and adjoint PSE. Stability calculations and N-factor correlations can be performed for both 2D/axisymmetric and general 3D configurations. ${ }^{44}$ Nonlinear PSE modules in LASTRAC have been used to study the effect of discrete roughness elements on crossflow transition. ${ }^{45}$ The governing equations in LASTRAC account for surface curvature and nonparallel mean flow.

\section{A. Pressure Coefficients}

\section{Results and Discussion}

Calculations were first performed for the case with no glove to compare with available experimental data to validate the CFD results. Good agreement (not shown) was achieved for the pressure distribution and lift coefficient. Computations were then carried out for the G-3 aircraft with the gloved swept-wing. The glove has a slightly larger leading-edge sweep of about $34.6^{\circ}$ compared to $31.7^{\circ}$ for the rest of the wing. The flow conditions for the present computations are: $\mathrm{M}=0.75, \mathrm{Re}_{\mathrm{c}}=22 \times 10^{6}, \mathrm{H}=38,840 \mathrm{ft}$, and angle of attack (AoA) $=3.5^{\circ}$. The unstructured-grid generated for this case is depicted in Fig. 4. The grid has a total of about 27 million nodes. The solution is obtained in two ways. First, turbulent flow is computed everywhere using the S-A model and the solution in this case converges rapidly. Second, turbulent flow was assumed everywhere except on the glove up to just upstream of the shock and this solution also converged. Results for the two computations are compared in Fig. 5. Pressure coefficients are essentially the same in the two cases except near the shock where the partly laminar computation shows a kink due to the abrupt turn-on of the turbulence model. We note that the boundary-layer grid used here is not sufficiently fine for this Navier-Stokes solution to be used directly for the stability analysis. Therefore, such analysis will be based on boundary-layer computations using the Cp distributions derived from the Navier-Stokes solution and for that purpose either a turbulent or laminar CFD computation for the glove could be used.

Figure 6 gives pressure distributions for three selected span stations ( $y=204$ in, 234 in and 264 in) on the glove. Only the suction side results are of particular interest here. The Cp results generally exhibit favorable gradients as desired. Along the mid-span station on the glove, $y=234$ ", the pressure gradient is favorable all the way to the shock and should result in crossflow dominated transition. Along the inboard glove station $y=204$ ", there is a strong favorable pressure gradient up to $\mathrm{x} / \mathrm{c}=0.14$ which would result in stronger crossflow instability at this inboard location as compared to the $\mathrm{y}=234$ " station. However, the nearly flat roof top distribution between $\mathrm{x} / \mathrm{c}=0.14$ and 0.4 is expected to bring TS instability. At the outboard station $y=264$ ", the Cp distribution is nearly flat between $\mathrm{x} / \mathrm{c}=.02$ and .2 ; therefore, TS instability should dominate in this region, followed by stronger crossflow growth 
downstream of $\mathrm{x} / \mathrm{c}=.2$ where stronger favorable gradients are present. These observations will be confirmed by performing linear stability computations next.

\section{B. Linear Stability Analysis of the G-3 Glove Boundary-Layer}

Streamwise pressure distributions at the three spanwise stations on the glove were extracted from the CFD solution and used for computing mean flow using the boundary layer code BLSTA. ${ }^{46}$ The boundary layer profiles thus computed were analyzed using the LASTRAC code under the quasi-parallel flow assumption. This mode of analysis is commonly referred to as Linear Stability Theory (LST). Three-dimensional boundary layers are unstable to both stationary and traveling crossflow disturbances, with traveling disturbances having much higher growth rates based on linear stability analysis. The question of whether stationary or traveling disturbances are relevant in the transition process primarily depends upon the receptivity of these disturbances to external forcing. Surface roughness induces stationary disturbances, while free-stream turbulence induces traveling disturbances. The effect of free stream turbulence on crossflow-induced transition was studied by Deyhle and Bippes ${ }^{47}$ in wind tunnels, where it was found that stationary disturbances dominate transition at low turbulence levels, while traveling instability waves become dominant when turbulence levels exceed 0.2 percent $(T u>0.2)$. Saric et all. ${ }^{23}$ have argued that since the turbulence level in flight is low, only stationary disturbances are relevant in flight transition making the boundary-layer subject to DRE control. Therefore, the present analysis is limited to stationary disturbances. It is important to note that in cases where traveling disturbances dominate the transition process, DRE might not be relevant in delaying transition.

For stationary $(f=0 \mathrm{~Hz})$ crossflow instability analysis, computations were performed for disturbances of various spanwise wavelengths which were held fixed as the $\mathrm{N}$ factor computations proceeded in the downstream direction. Here, $\mathrm{N}$ is given as

$$
N=\int \sigma d s
$$

where $\sigma$ is the disturbance growth rate computed using stability analysis and $s$ represents the surface distance along the path of integration, which is either in the chordwise direction or along the inviscid streamlines. Disturbances grow by a factor of $\mathrm{e}^{\mathrm{N}}$ prior to transition, where the value of $\mathrm{N}$ is empirically determined.

The results for disturbance wavelengths of $3 \mathrm{~mm}$ to $18 \mathrm{~mm}$ are shown in Fig 7, which confirm our conjecture based on the $\mathrm{Cp}$ distributions. At the inboard location, crossflow $\mathrm{N}$ factor increases rapidly and a value of 9 is reached at $\mathrm{x} / \mathrm{c}=0.14$. At the mid-span of the glove, $\mathrm{N}$ factor growth is more gradual and an $\mathrm{N}$ of 9 is reached at about $\mathrm{x} / \mathrm{c}=.44$. For the outboard location, $\mathrm{N}$ factors are much smaller initially but stronger growth downstream of $\mathrm{x} / \mathrm{c}=.25$ yields $\mathrm{N}=9$ at $\mathrm{x} / \mathrm{c}=.44$ as for the mid-span location. We use the value $\mathrm{N}=9$ for illustrative purposes and do not imply that this would necessarily correlate with transition in this case. The value of $\mathrm{N}$ at transition depends upon surface finish near the leading edge. Saric et al. ${ }^{23}$ noted that $\mathrm{N}$ reached a value of 14 for the polished leading edge in the Cessna O-2 flight experiment. For the G-3 glove, this value is reached at $\mathrm{x} / \mathrm{c}=.52, .58$ and .56 for the inboard, mid-span and outboard locations, respectively.

Computations are next performed for TS disturbances of various frequencies ranging from 1,500 to $6,000 \mathrm{~Hz}$; the results are presented in Fig. 8. These results are obtained by holding wave angle fixed with respect to the inviscid streamline. The value of wave angle is selected to be $0^{\circ}$ in this case, i.e., the wave vector is assumed to align with the streamline. The results show that the $\mathrm{N}$ factor for TS waves is the highest $(\mathrm{N}=6)$ at the inboard location followed by the outboard location $(\mathrm{N}=5.5)$ with mid-span location having the lowest value $(\mathrm{N}=4)$. These values are again consistent with our expectations from the Cp distributions. The effect of TS wave orientation is studied in Fig. 9 where we show results for wave angles of $-20^{\circ}, 0^{\circ}, 20^{\circ}$ and $30^{\circ}$ for the mid-span location. The $\mathrm{N}$ factor for TS waves increases with wave angle, reaching 5.5 at $30^{\circ}$ as compared to 4 for the $0^{\circ}$ wave angle case. Some comments on the TS N factor computation strategies will be made in the next section.

The above computations have been made assuming adiabatic wall conditions. During a short duration test flight, the glove temperature would start out from being at atmospheric value at sea level. As the aircraft approaches the design altitude, the surrounding temperature drops much more rapidly than the glove temperature. Therefore, before an equilibrium can be established, conditions of $\mathrm{T}_{\mathrm{w}}>\mathrm{T}_{\mathrm{adb}}$ can exist. It is well known that TS instability is very sensitive to wall heat transfer and, in particular, experimental data in Ref. 48 shows that transition Reynolds number varies as $\left(\mathrm{T}_{\mathrm{w}} / \mathrm{T}_{\mathrm{adb}}\right)^{-7}$. In order to assess the wall temperature effect for the glove boundary layer, calculations were 
made by assuming $\mathrm{T}_{\mathrm{w}}=1.1 \mathrm{~T}_{\text {adb }}$ for the mid-span location assuming wave orientation of $30^{\circ}$. Results in Fig. 10 show that the $\mathrm{N}$ factor reaches a value of 8 for this temperature condition as compared to 5.5 for the adiabatic case in Fig. 9. It is important that the NLF experiment be performed only after the glove temperature has dropped sufficiently close to the adiabatic wall temperature. This can be accomplished via a 'cold soak' where the aircraft flies at a higher altitude (i.e., colder atmospheric temperature) before descending to the prescribed test altitude.

Based on the significant spanwise variations of $\mathrm{Cp}$ on the G-3 glove noted above, and the associated stability results, it is recommended that the glove be redesigned to minimize the spanwise variations. This redesign is currently underway.

\section{PSE Analysis}

As noted above, swept-wing transition involves nonlinear growth of crossflow disturbances followed by breakdown via high frequency secondary instabilities ${ }^{11}$ and this evolution is readily computed by nonlinear Parabolized Stability Equations (PSE) and secondary instability analyses. ${ }^{45} \mathrm{~A}$ crucial piece of missing information is the initial disturbance level induced by roughness. Carpenter et al. ${ }^{49}$ have studied receptivity of incompressible swept-wing boundary layer to surface roughness using Linearized Navier-Stokes (LNS) equations. For the Cessna O-2 case, they were able to demonstrate that disturbance amplitude internalized in the boundary-layer differed by two orders of magnitude (approximately $\mathrm{e}^{5}$ ) between surface roughness distributions modeled after surface height measurements for painted and polished surfaces, which is roughly consistent with the observation of Saric et al. ${ }^{23}$ that transition moved forward to about $30 \%$ chord when the leading-edge was painted as compared to the transition location at $80 \%$ chord for the polished leading-edge. We note that Ref. 49, after detrending the raw data of Ref. 23, the computed rms surface roughness height was $0.09 \mu \mathrm{m}$ and $6.5 \mu \mathrm{m}$ for the polished and painted surfaces, respectively, as compared to the raw rms values of $.3 \mu \mathrm{m}$ and $1 \mu \mathrm{m}$ quoted in Ref. 23.

Receptivity studies require spectral information about surface finish, which will not be available for the G-3 glove until it is designed, manufactured and measured. In the absence of such knowledge, the only alternative is to assume an initial disturbance level and then parametrically study its impact on secondary instability breakdown. Such an analysis was conducted by Ref. 45 for an infinite swept-wing to investigate DRE effectiveness. Their analysis was performed for a swept airfoil glove ${ }^{50}$ intended for a Gulfstream-II (G-2) aircraft wing, a hypothetical predecessor to the current G-3 effort. Computations were performed for a Mach number of 0.75, chord Reynolds number of $17 \times 10^{6}$ and wing leading-edge sweep of $30^{\circ}$. Nonlinear PSE analysis was used to first compute the development of stationary crossflow vortices and then secondary instability analysis was performed with a view to assess the feasibility of roughness based control methodology at high Reynolds numbers. It was noted that a “... broad spectrum of stationary crossflow disturbances amplify and, while it may be possible to control a specific target mode using Discrete Roughness Elements (DREs), nonlinear interaction between control and target modes may yield strong amplification of the difference mode that could have an adverse impact on the transition delay using spanwise periodic roughness elements." Since these conclusions were drawn based on assumed initial amplitudes of disturbances, they can be characterized as qualitative at best. Definitive conclusions can only be drawn when initial modal amplitudes are available from a careful receptivity analysis for a given surface finish.

A Compressible LNS code is under-development but is currently not available to carry out receptivity computations for the G-3, similar to those in Carpenter et al. ${ }^{49}$ In the meantime, it will be instructive to carry out PSE analysis as a risk reduction exercise, particularly since the planned range of flight Reynolds numbers is even higher than the G-2 case of Ref. 45. Nonlinear PSE analysis using the LASTRAC code can be performed only for an infinite swept-wing and therefore rest of the analysis will be performed under this assumption. The G-3 glove geometry (Fig. 3) was developed from an infinite-swept airfoil design and we compare the Cp distribution for that airfoil (i.e., target $\mathrm{Cp}$ for the glove design) with the mid-span $\mathrm{Cp}$ for the 3D glove in Fig. 11. The two distributions are similar near the leading-edge but there is a large change in slope of the glove $\mathrm{Cp}$ ahead of the shock, which gives rise to larger $\mathrm{N}$ factors in that region noted earlier in Fig 7. $\mathrm{N}$ factor computations based on linear stability analysis for the infinite-swept airfoil are shown in Fig. 12 where maximum $\mathrm{N}$ factors for the $22 \times 10^{6}$ case reach about 10.6 at $\mathrm{x} / \mathrm{c}=0.6$ as compared to 14 in Fig. 7 (b). According to Saric's LST-based $\mathrm{e}^{14}$ criterion $^{23}$ for polished leadingedges, transition should take place on the glove at $\mathrm{x} / \mathrm{c}=0.58$ for the current Reynolds number of $22 \times 10^{6}$, but the boundary-layer would remain laminar if a redesigned glove can maintain the target infinite-swept wing pressure distribution shown in Fig. 11. Figure 12 also contains $\mathrm{N}$ factor results for $\operatorname{Re}_{\mathrm{c}}=17 \times 10^{6}$ and $27.5 \times 10^{6}$ and transition will not occur in the highest Reynolds number case for the polished leading-edge based on the $\mathrm{e}^{14}$ LST criterion. Transition for the target $\mathrm{Cp}$ distribution should occur at higher chord Reynolds numbers or with painted 
(roughened) leading-edges. In order to achieve transition at $\operatorname{Re}_{\mathrm{c}}=22 \times 10^{6}$ with polished leading-edge, the slope of the $\mathrm{Cp}$ curve must be increased and this should also help stabilize the TS waves.

The first step in nonlinear analysis is to perform linear PSE computations to determine control and target modes, as was done in Ref. 45 Their results presented in Fig. 13, for example, show that stationary modes over a broad range of spanwise wavelengths $(4 \mathrm{~mm}<\lambda<17 \mathrm{~mm}$ ) attain a peak $\mathrm{N}$ factor greater than 8 , based on linear PSE analysis of the G-2 airfoil. The $8 \mathrm{~mm}$ wavelength achieved the highest $\mathrm{N}$ factor of about 12.3, and this wavelength was selected as the target mode with the $2.67 \mathrm{~mm}$ wavelength acting as the control mode in their nonlinear analysis. It would be instructive to perform linear PSE analysis for the G-3 design airfoil to determine the target and control modes for DRE application. These results are presented in Fig. 14 and it is clear that the highest $\mathrm{N}$ factor in this case is substantially lower than the LST result shown in Fig. 12. It can thus be argued that if stationary modes constitute the dominant route to breakdown, transition will not take place for this case with $\operatorname{Re}_{\mathrm{c}}=22 \times 10^{6}$ as the highest $\mathrm{N}$ factor is only about 4.6. The PSE N factor is lower by almost 6 as compared to the results based on LST, which is an unexpected result and it is important to investigate this further. Therefore, rest of the paper will focus on this dramatic drop in $\mathrm{N}$ factor and a nonlinear PSE analysis is deferred to a future date.

Parabolized Stability Equations account for nonparallel and surface curvature effects, while these effects are ignored in LST. References ${ }^{51-52}$ showed that nonparallel effect is usually destabilizing and surface curvature is stabilizing as compared to computations based on the quasi-parallel assumption of LST. Comparison of the results in Fig. 12(b) and Fig. 14 implies that the surface curvature effect is much stronger than the nonparallel effect in this case. We study this in Fig. 15 where we present the results for $\lambda=9 \mathrm{~mm}$ using (a) quasi-parallel theory with no curvature, (b) quasi-parallel theory with curvature, (c) PSE with no curvature (i.e., nonparallel effect only) and (d) PSE with curvature. The last option is the only consistent approach in that it accounts for all the relevant effects of the same order. The $\mathrm{N}$ factor using PSE drops from 14.5 in the no-curvature case to only about 4.1 when curvature terms are included. Figure 16 presents the results for the G-2 airfoil with and without curvature using $\lambda=8 \mathrm{~mm}$ and in this case the $\mathrm{N}$ factor drops from about 17 (PSE, no curvature) to 12.3 (PSE, with curvature). While the two (G-2 and G-3) Cp distributions are different, it is still remarkable that the maximum $\mathrm{N}$ factor (for $\lambda=12 \mathrm{~mm}$ ) is only 4.6 for the G-3 airfoil at $\operatorname{Re}_{c}=22 \times 10^{6}$ as compared to 12.3 for the G-2 airfoil at the lower $\operatorname{Re}_{c}=17 \times 10^{6}$. Thus, the drop in maximum $\mathrm{N}$ factor due to curvature is 4.7 and 9.9 for the G-2 and G-3 airfoils, respectively; the stabilizing effect is much stronger in the latter case. Since the maximum $\mathrm{N}$ factor difference between LST and PSE is about 1.7 and 6 for the G-2 and G-3 airfoils, respectively, use of the LST approach in design computations is justified in the former case but will introduce large errors in the latter case.

The centrifugal term in the normal momentum equation that induces Gortler instability ${ }^{53}$ in boundary-layers over concave surfaces is also the term that induces the stabilizing effect of convex curvature on crossflow vortices. ${ }^{51}$ Therefore, Gortler number should provide a measure of the effect of convex curvature on crossflow instability as it does for centrifugal instability on concave surfaces. In order to understand the disparate effect of curvature for the G-2 and G-3 airfoils, we plot airfoil geometries and Gortler number for the two cases in Fig. 17. Here, Gortler number is defined as

$$
G_{\theta}=R e_{\theta} \sqrt{\theta \kappa}
$$

where $\theta$ is the chordwise boundary-layer momentum thickness and $\kappa$ is surface curvature. The comparison in Fig. 17 clearly shows that the Gortler number is much higher for the G-3 airfoil; and this explains the stronger stabilizing effect in this case. Figure 17 also gives Gortler number distributions for the G-3 case with $\operatorname{Re}_{\mathrm{c}}=17 \mathrm{x} 10^{6}$ and $27.5 \mathrm{x}$ $10^{6}$. The oscillations in the Gortler number for the G-3 are the direct result of oscillations in surface curvature and this induces oscillations in the growth rate noticed in Fig. 15.

$\mathrm{N}$ factor results for the three Reynolds numbers $\left(\operatorname{Re}_{\mathrm{c}}=17 \times 10^{6}, 22 \times 10^{6}\right.$ and $\left.27.5 \times 10^{6}\right)$ are compared in Fig. 18. The peak $\mathrm{N}$ factors for the three cases are 3.3, 4.6 and 6.6, respectively. The value of 3.3 is to be compared with $\mathrm{N}=$ 12.3 for the G-2 case at the same Reynolds number of $17 \times 10^{6}$. One thing is clear from this analysis: for the lowest Reynolds number, the boundary-layer will remain laminar up to $\mathrm{x} / \mathrm{c}=0.6$ yielding a transition Reynolds number of $10.2 \times 10^{6}$. This is almost twice the Reynolds number achieved in the F-14 NLF flight experiment at the same sweep angle. 
If transition is induced by stationary crossflow vortices (a necessary condition for the applicability of DRE technology), then the above results suggest that transition will not occur for the two lowest Reynolds numbers and, therefore, the DRE control experiments are not relevant even for the $\operatorname{Re}_{\mathrm{c}}=22 \times 10^{6}$ case. Crossflow-induced transition is likely for the highest Reynolds number case but perhaps at relatively large $\mathrm{x} / \mathrm{c}$ with little scope for DRE control, except with roughened glove leading-edges. However, at this Reynolds number, TS N factors reach values in excess of 8 for adiabatic wall conditions and TS instability may become the dominant cause of transition. Therefore, it is important that the glove design be changed to allow steeper favorable pressure gradients to suppress TS waves. This will also result in higher stationary crossflow disturbance growth using PSE, which can then be suppressed or delayed via DRE in order to address the primary objective of the flight experiment.

It is important to reiterate that the success of DRE rests upon the premise that traveling crossflow disturbances are not generated in the 3D boundary-layer because of the low turbulence levels in $\mathrm{flight}^{23}$. Based on the experimental data of Refs. ${ }^{47,54}$, it was argued in Ref. 55 that transition is caused by stationary disturbances when $T u$ $\sim .02 \%$ and dominated by traveling instability waves when $T u \sim .15 \%$. Masad and Abdelnaser ${ }^{56}$ analyzed the data from the swept cylinder experiment of Ref. 57 and argued that transition was induced by traveling instability waves in this case where $T u \sim .15 \%$. Their $\mathrm{N}$ factor analysis, which included nonparallel and surface curvature effects, yielded mean $\mathrm{N}$ values of 14.9 and 7.4 for traveling and stationary disturbances, respectively. Takagi and Itoh ${ }^{58}$ noted that, as they continued to clean the surface of their swept cylinder, stationary disturbances gave way to traveling instability waves in their low disturbance wind tunnel experiment. It should be noted, however, that the swept cylinder used in Ref. 58 had an order of magnitude higher leading-edge radius than the G-3 airfoil and the associated thicker boundary-layer in that case would be much less sensitive to surface roughness. For the 757 HLFC flight experiment, transition location could be well-correlated with a traveling disturbance $\mathrm{N}$ factor of 9.6 calculated using PSE. This result does not necessarily imply that transition in the 757 experiment was caused by traveling instability waves as leading-edge suction distribution is known to induce a roughness effect, which would yield higher initial amplitude for stationary disturbances requiring smaller amplification by the boundary layer via linear mechanism.

Traveling disturbances, if excited at a sufficiently high amplitude, grow much more than the stationary ones and in that case would dominate transition. Linear PSE results for traveling disturbances for $\operatorname{Re}_{\mathrm{c}}=22 \times 10^{6}$ are presented in Fig. 19 using LST and PSE. First, we note that PSE N factor values are marginally lower than the LST value in this case. Second, the highest PSE N factor is about 15.6 as compared to only 4.6 in Fig. 14(b) for the stationary disturbances. Thus, PSE N factors (that include nonparallel and surface curvature effects) differ by almost 11 in this case for traveling and stationary disturbances. The difference drops to about 6 when LST is used in the analysis. It is not known if traveling disturbances could begin to dominate crossflow transition when $\mathrm{N}$ factors differ by about 11 . However, whether the difference in traveling and stationary $\mathrm{N}$ factors at small $\mathrm{x} / \mathrm{c}$ is sufficiently large to overcome their disparate initial amplitudes is the only relevant question. This is because when disturbances grow to nonlinear amplitudes, results of linear analysis are no longer applicable and an $\mathrm{N}$ factor difference of 11 near the end of the domain of interest may be of no significance.

As noted above, DRE design requires that the boundary-layer is subcritical to TS-induced transition. In computing TS $\mathrm{N}$ factors (Figs. 8-10), the engineering approach of fixing wave angle with respect to inviscid streamlines (cf., Ref. 59) was employed. However, there is no physical basis for this approach and the only rational way to perform $\mathrm{N}$-factor analysis for infinite span wings is to assume constant spanwise wavelengths as was done in the crossflow analysis above (see also Ref. 60). For the G-3 airfoil, TS wave computations have been carried out using LST for various disturbance frequencies and the frequency of $2000 \mathrm{~Hz}$ gave the highest $\mathrm{N}$ factor. Results of these computations for the most amplified frequency are shown in Fig. 20(a) for several wave angles ranging from $0^{\circ}$ to $50^{\circ}$. $\mathrm{N}$ factor continues to increase with wave angle as shown in the figure. The PSE results, with holding spanwise wavelengths fixed, are shown in Fig. 20(b) for the $2000 \mathrm{~Hz}$ frequency and several different disturbance wavelengths. Stability characteristics ( $\mathrm{N}$ factor, disturbance growth rate, wave angle and phase speed) derived from these PSE computations are presented in Fig. 21 for two locations $(\mathrm{x} / \mathrm{c}=.25$ and .45$)$. Wave angle increases with decreasing wave length, with highest $\mathrm{N}$ factor for a wave angle of about $70^{\circ}$. Instability for the selected frequency belongs to both the TS and traveling crossflow type. The disturbances with larger wavelengths belong to the TS family (viscous instability) while the disturbances with relatively smaller wavelengths are of traveling crossflow (inviscid instability) type. It is clear from the results that the switchover from one instability type to the other is not abrupt. For wave lengths $\lambda>60 \mathrm{~mm}$, phase speed is almost constant at about .4 when scaled with the free stream velocity, which is typical of TS waves. At small wave lengths, phase speed drops to a value of about .05, which is 
typical of traveling crossflow disturbances. At intermediate wave lengths, the instability is of mixed type. Traveling disturbances are sensitive to free stream turbulence level and, at low levels of turbulence, TS waves are more sensitive to the acoustic disturbance field. Therefore, whether or not traveling crossflow and TS waves are relevant in the transition process depends upon free stream turbulence level at flight altitudes and the aircraft acoustic field.

Definitive conclusions about transition mechanism in a 3D boundary-layer can only be drawn when information about external forcing as well as computational tools for receptivity prediction are available. It should now be possible to perform such an analysis to determine the effect of surface roughness (see Refs. ${ }^{45,49}$ ). However, we do not have sufficient information about turbulence characteristics (turbulence level and spectra) at flight altitudes and, therefore, quantitative prediction of receptivity of the G-3 glove boundary-layer to free-stream disturbance environment is not currently feasible, without which definitive conclusions cannot be drawn to completely rule out the role of traveling disturbances in flight and hence the need for physical experiments. If DRE control is demonstrated in flight at the selected Reynolds numbers, then that will provide an indirect evidence that traveling disturbances are not relevant in flight transition for transport aircraft even though they amplify much more within the framework of linear PSE. If the DRE control fails, then either the premise that only stationary crossflow disturbances are relevant in flight transition at all Reynolds numbers would be false or that the boundary-layer was not subcritical to TS-induced transition.

\section{Conclusions}

Computational analysis has been performed for the laminar flow glove designed for the Gulftream-III flight experiment planed under NASA's Environmentally Responsible Aviation Project to evaluate the effectiveness of the Discrete Roughness Elements (DRE) technology at high Reynolds numbers of relevance to transport aircraft. The Mach number, lift coefficient and sweep angle used in the analysis are $0.75,0.5$ and $34.6^{\circ}$, respectively. This analysis is limited to the suction side, which is the designated test surface for demonstrating passive laminar flow control using DREs. Computational tools included FUN3D ${ }^{25}$ unstructured-grid Navier-Stokes code and LASTRAC ${ }^{26}$ for analyses based on Linear Stability Theory (LST) and Parabolized Stability Equations (PSE). The following conclusions can be drawn from the analysis:

- For the current design, natural laminar flow should be achievable up to $\mathrm{x} / \mathrm{c}=0.6$ at $\mathrm{Re}_{\mathrm{c}}=17 \mathrm{x} 10^{6}$ yielding a transition Reynolds number of $10.2 \times 10^{6}$, which is twice the Reynolds number ever achieved in an NLF experiment at the selected sweep angle of $34.6^{\circ}$.

- There are significant spanwise variations in $\mathrm{Cp}$; therefore, the glove needs to be redesigned to minimize these variations.

- To demonstrate DRE technology, the new design needs to have stronger favorable pressure gradient in order to weaken TS growth, and to support stronger stationary crossflow instability that could then be controlled via DRE.

- During flight testing, attention needs to be given to maintain adiabatic wall temperature for TS control.

- As an unexpected outcome of the computational analysis, surface curvature was found to exert a very strong stabilizing influence on stationary crossflow disturbances for the present design. PSE $\mathrm{N}$ factors (including nonparallel and surface curvature effects) for stationary disturbances are smaller by about 6 when compared to LST (quasi-parallel, without curvature) results for the three chord Reynolds numbers $\left(\operatorname{Re}_{\mathrm{c}}=17 \times 10^{6}, 22 \times 10^{6}\right.$ and $\left.27.5 \times 10^{6}\right)$ computed. For the intermediate Reynolds number case, the net $\mathrm{N}$ factor drop of 6 consisted of an increase in $\mathrm{N}$ factor of about 4 owing to the nonparallel effect and a decrease in $\mathrm{N}$ factor of about 10 owing to the surface curvature effect.

- If in-flight transition indeed happens via stationary crossflow disturbances, then transition may also be delayed by using convex surface curvature as a control parameter.

- In contrast with the above results for stationary disturbances, the PSE $\mathrm{N}$ factor for traveling crossflow disturbances was lower by only about 1 when compared to the values obtained using LST. The disparate effect of using PSE helps increase the difference in overall growth of traveling and stationary disturbances. PSE $\mathrm{N}$ factors for traveling disturbances are higher by almost 11 as compared to the values computed for 
stationary disturbances; the difference drops to about 6 when LST is used (i.e., nonparallel and surface curvature effects are ignored) in the analysis.

- The role, if any, of traveling crossflow disturbances during transition over the present glove design cannot be currently ascertained computationally due to the lack of knowledge (level and spectra) of free stream turbulence at the flight altitudes.

\section{Acknowledgements}

The present work is part of a collaborative effort with Professor W. S. Saric, Professor H. L. Reed and their research group at Texas A\&M University as well as the DRE LFGE team at Dryden. This work was performed in support of NASA's Environmentally Responsible Aviation (ERA) Project.

\section{References}

1. Hefner, J. N. and Bushnell, D. M., "An Overview of Concepts for Aircraft Drag Reduction", AGARD Report No. 654, Special Course on Concepts for Drag Reduction, pp. 1-30, 1977.

2. Marec, J-P., "Drag Reduction: a Major Task for Research," CEAS/DragNet European Drag Reduction Conference 2000, Potsdam, June 2000.

3. Washburn, A., "Drag Reduction Status and Plans - Laminar Flow and AFC," Oral Presentation at AIAA Aero Sciences Meeting, Orlando, FL, January 4-7, 2011.

4. Bushnell, D. M. and Tuttle, M. H., "Survey and bibliography on attainment of laminar flow control in air using pressure gradient and suction,” Vol. I, NASA RP-1035, 1979.

5. Bushnell, D. M., "Overview of aircraft drag reduction technology," in Special course on skin friction drag reduction, AGARD Report 786, 1992.

6. Joslin, R. D., “Aircraft Laminar Flow Control," Ann. Rev. Fluid Mech., Vol. 30, 1998, pp. 1-29.

7. Green, J. E., "Laminar Flow Control - back to the Future?," AIAA Paper 2008-3738, 2008.

8. Spalart, P. R., and McLean, J. D., "Drag Reduction: enticing turbulence, and then an industry," Phil. Trans. R. Soc. A, Vol. 369, 2011, pp. 1556-1569.

9. Wilkinson, S. P. and Malik, M. R., "Stability Experiments in the Flow over a Rotating Disk," AIAA J., Vol. 23, 1985, pp. 588-595.

10. Balachandar, S., Streett, C. L., and Malik, M. R., "Secondary Instability in a Rotating Disk Flow," J. Fluid Mech., Vol. 242, 1992, pp. 323-347.

11. Malik, M. R., Li, F., Chang, C.-L., "Crossflow disturbances in three-dimensional boundary layers: Nonlinear development, wave interaction and secondary instability," J. Fluid Mech., Vol. 268, 1994, pp. 1-36.

12. Malik, M. R., Li, F., Choudhari, M., and Chang, C.-L., "Secondary Instability of Crossflow Vortices and Swept-Wing Boundary-Layer Transition,” J. Fluid Mech., Vol. 399, 1999, pp. 85-115.

13. Kohama, Y., Saric, W. S., and Hoos, J. A., "A high-frequency secondary instability of crossflow vortices that leads to transition," in Boundary Layer Transition and Control, Proc. Royal Aeronautical Society, Cambridge, 8-12 April, 1991, London, UK.

14. White, E. B. and Saric, W. S., "Secondary instability of crossflow vortices," J. Fluid Mech., Vol. 525, 2005, pp. 275308.

15. Maddalon, D., Fisher, D., Jennett, L., and Fischer, M., "Simulated airline service experience with laminar flow control leading-edge system,” NASA Symposium on NLF and LFC Research, NASA CP 24587, 1987, pp. 195-218.

16. Boeing Commercial Airplane Group, High Reynolds Number Hybrid Laminar Flow Control (HLFC) Flight Experiment Final Report. Volume I: D6-55648-1 through Volume 6: D6-55628-6, 1993.

17. Pfenninger, W., "Laminar Flow Control - Laminarization," AGARD Report No. 654, Special Course on Drag Reduction, 1977.

18. Anders, S. G. and Fischer, M. C., "F-16XL-2 Supersonic laminar Flow Control Flight Test Experiment," NASA TP1999-209683, 1999.

19. Saric, W.S., Carrillo, R. B. Jr., and Reibert, M.S., "Nonlinear stability and transition in 3-D boundary layers," Meccanica 33, 1998, pp. 469-487.

20. Chang, C.-L. and Choudhari, M., "Boundary-Layer Receptivity and Integrated Transition Prediction," AIAA 2005$0526,2005$. 
21. Wassermann, P. and Kloker, M., "Mechanisms and control of crossflow-vortex induced transition in a threedimensional boundary layer," J. Fluid Mech., Vol. 456, 2002, pp. 49-84.

22. Saric, W. S., Carpenter, A. L., and Reed, H. L., "Laminar Flow Control Flight Tests for Swept Wings: Strategies for LFC," AIAA Paper 2008-3834, 2008.

23. Saric, W. S., Carpenter, A. L., and Reed, H. L., "Passive Control of Transition in Three-Dimensional Boundary Layers, with Emphasis on Discrete Roughness Elements," Phil. Trans. R. Soc. A, Vol. 369, 2011, pp. 1352-1364.

24. Belisle, M. J., Roberts, M.W., Tufts, M. W., Tucker, A. A., Williams, T., Saric, W.S., and Reed, H. L., "Design of the Subsonic Aircraft Roughness Glove Experiment (SARGE)", AIAA Paper 2011-???.

25. http://fun3d.larc.nasa.gov/

26. Chang, C.-L., "The Langley Stability and Transition Analysis Code (LASTRAC): LST, Linear and Nonlinear PSE for 2-D, Axisymmetric, and Infinite Swept Wing Boundary Layers," AIAA Paper 2003-0974, 2003.

27. Wagner, R. D., Maddalon, D. V., Bartlett, D. W., Collier, F. S., and Braslow, A. L., "Laminar Flow Flight Experiments - A Review," in Natural Laminar Flow and Laminar Flow Control, Eds. R. W. Barnwell and M. Y. Hussaini, pp. 2371, Springer-Verlag, New York, 1992.

28. Wetmore, J. W., Zalovcik, J. A., and Platt, R. C., "A Flight Investigation of the Boundary-Layer Characteristics and Profile Drag of the NACA 35-215 Laminar Flow Airfoil at High Reynolds Numbers," NACA L-532, 1941.

29. Gray, W. E. and Fullam, P. W. J., "Comparison of Flight and Tunnel Measurements of Transition on a Highly Finished Wing (King Cobra)," RAE Report Aero 2383, 1945.

30. Boeing Commercial Airplane Company, "Flight Survey of the 757 Wing Noise Field and its Effect on Laminar Boundary Layer Transition,” NASA CR-178217, Vol. I - Program Description and Data Analysis, March 1987.

31. Boeing Commercial Airplane Company, "F-111 Natural Laminar Flow Glove Flight Test Data Analysis and BoundaryLayer Stability Analysis", NASA CR-166051, January 1984.

32. Wagner, R. D., Maddalon, D. V., Bartlett, D. W., Collier, F. S., and Braslow, A. L., "Laminar Flow Flight Experiments," in Proceedings of the Transonic Aerodynamics Symposium, NASA Langley Research Center, NASA CP 3020, 1988.

33. Boltz, F. W., Kenyon, G. C., and Alllen, C. Q., "Effects of Sweep Angle on the Boundary-Layer Stability Characteristics of an Untapered Wing at Low Speeds", NASA TN D-338, 1960.

34. Braslow, A. L. and Visconti, F., "Investigation of Boundary-Layer Reynolds Number for Transition on an NACA Airfoil in the Langley Two-Dimensional Low Turbulence Pressure Tunnel," NACA TN 1704, October 1948.

35. Drake, A. and Solomon, W. D., "Flight Testing of a 30-Degree Sweep laminar Flow Wing for a High-Altitude Long Endurance Aircrfat," AIAA Paper 2010-4571, 2010.

36. Schrauf, G., "Large-Scale laminar-Flow Tests Evaluated with Linear Stability Theory," J. Aircraft, Vol. 41, No. 2, 2004, pp. 224-230.

37. Schrauf, G., "Status and Perspectives of laminar Flow," CEAS/KATnet Conference on Key Aerodynamic Technologies, 20-22 June 2005, Bremen, Germany.

38. Nielsen, E. J., Lu, J., Park, M. A., and Darmofal, D. L., “An Implicit, Exact Dual Adjoint Solution Method for Turbulent Flows on Unstructured Grids," Computers and Fluids, Vol. 33, No. 9, 2004, pp. 1131-1155.

39. Roe, P. L., “Approximate Riemann Solvers, Parameter Vectors, and Difference Schemes," Journal of Computational Physics, Vol. 43, 1981, pp. 357-372.

40. Diskin, B., Thomas, J. L., Nielsen, E. J., Nishikawa, H., and White, J. A., "Comparison of Node-Centered and CellCentered Unstructured Finite-Volume Discretizations: Viscous Fluxes," AIAA Journal , Vol. 48, No. 7, July 2010, pp. 1326-1338.

41. Spalart, P. R. and Allmaras, S. R., "A One-Equation Turbulence Model for Aerodynamic Flows," La Recherche Aerospatiale, Vol. 1, No. 1, 1994, pp. 5-21.

42. Pirzadeh, S., "Progress Toward a User-Oriented Unstructured Viscous Grid Generator," AIAA Paper 96-0031, 1996.

43. Fletcher, H., Dryden Flight Research Center, Private Communication, 2010.

44. Chang, C.-L., "LASTRAC.3d: Transition Prediction in 3D Boundary Layers," AIAA Paper 2004-2542, Portland, Oregon, Jun. 2004.

45. Li, F., Choudhari, M., Carpenter M., Malik, M. R., Chang, C.-L., and Streett, C., "Roughness Based Crossflow Transition for a Swept Wing Airfoil Design,” AIAA Paper 2010-4380, June 2010.

46. Wie, Y.-S., "BLSTA - A Boundary Layer Code for Stability Analysis," NASA CR 4481, 1992.

47. Deyhle, H., and Bippes, H., "Disturbance Growth in an unstable three-dimensional boundary layer and its dependence on environmental conditions," J. Fluid Mech., Vol. 316, 1996, pp. 73-113.

48. Dougherty, N. S., and Fisher, D. F., "Boundary Layer Transition on a 10-deg Cone: Wind Tunnel/Flight Data Correlation," AIAA Paper 80-0164, 1980.

49. Carpenter, M. H., Choudhari, M. M., Li, F., Streett, C. L., and Chang, C.-L., "Excitation of Crossflow Instabilities in a Swept Wing Boundary Layer,” AIAA Paper 2010-378, 2010. 
50. Belisle, M., Neale, T., Reed, H., and Saric, W., "Design of a Swept-Wing laminar Flow Control Flight Experiment for Transonic Aircraft," AIAA Paper 2010-4381, 2010.

51. Malik, M. R. and Balakumar, P., "Linear Stability of Three-Dimensional Boundary Layers: Effects of Curvature and Non-Parallelism," AIAA Paper 9300079, 1993.

52. Masad, J. A. and Malik, M. R., "Effects of body curvature and nonparallelism on the stability of flow over a swept cylinder," Phys. Fluids, Vol. 6 (7), 1994, pp. 2363-2379.

53. Saric, W. S., "Gortler Vortices," Annual Review of Fluid Mechanics, 26, 1994, pp. 379-409.

54. Radeztsky, R. H., Reibert, M. S., Saric, W. S., and Takagi, S., "Effect of Micron-Sized Roughness on Transition in Swept-Wing Flows," AIAA Paper 93-0076, 1993.

55. Crouch, J. D. and Ng, L. L., "Variable N-Factor Method for Transition Prediction in Three-Dimensional Boundary Layers,", AIAA J., Vol. 38, No. 2, 2000, pp. 211-216.

56. Masad, J. A. and Abdelnaser, A. S., "Transition in flow over a swept cylinder: Correlation with experimental data," Phys. Fluids, Vol. 8 (1), 1996, pp. 285-287.

57. Poll, D. I. A., "Some Observations of the Transition Process on the Wind-ward face of a Long Yawed Cylinder," J. Fluid Mech., Vol. 150, 1985, pp. 329-356.

58. Takagi, S. and Itoh, N., "Observation of Traveling Waves in the Three-Dimensional Boundary Layers along a Yawed Cylinder," Fluid Dynamics Research, Vol. 14, No. 4, 1994, pp. 167-189.

59. Streit, T., Horstmann, K. H., Schruaf, G., et al., "Complementary Numerical and Experimental Data Analysis of the ETW Telefona Pathfinder Wing Transition Tests," AIAA Paper 2011-0881, 2011.

60. Crouch, J., "Modeling Transition Physics for Laminar Flow Control," AIAA Paper 2008-3832, 2008. 


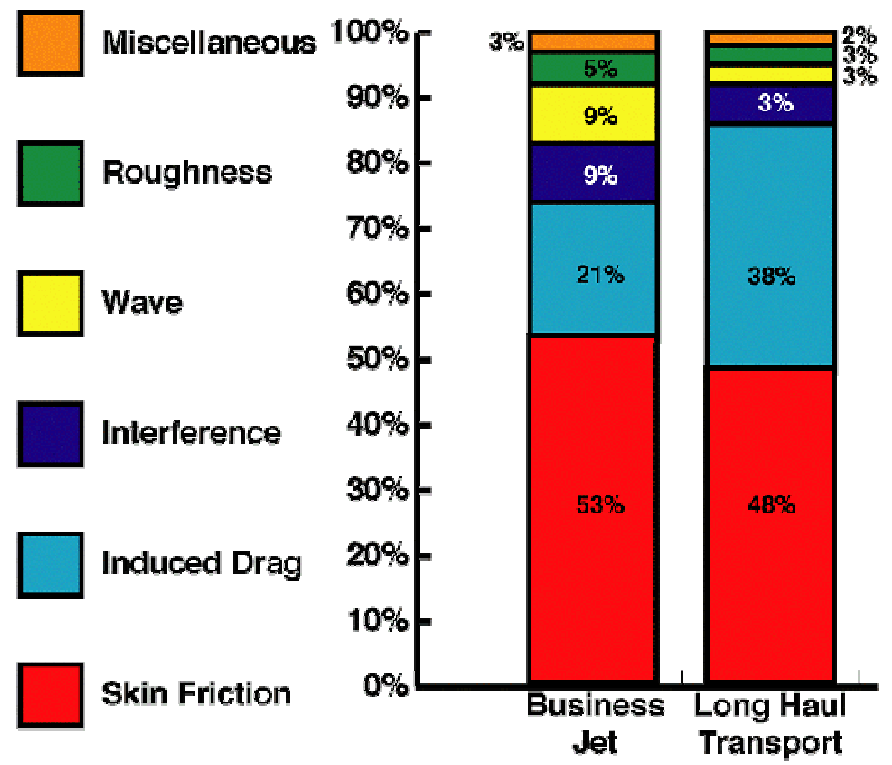

Figure 1. Drag budget for business jets and transport aircraft (from Washburn ${ }^{3}$ )

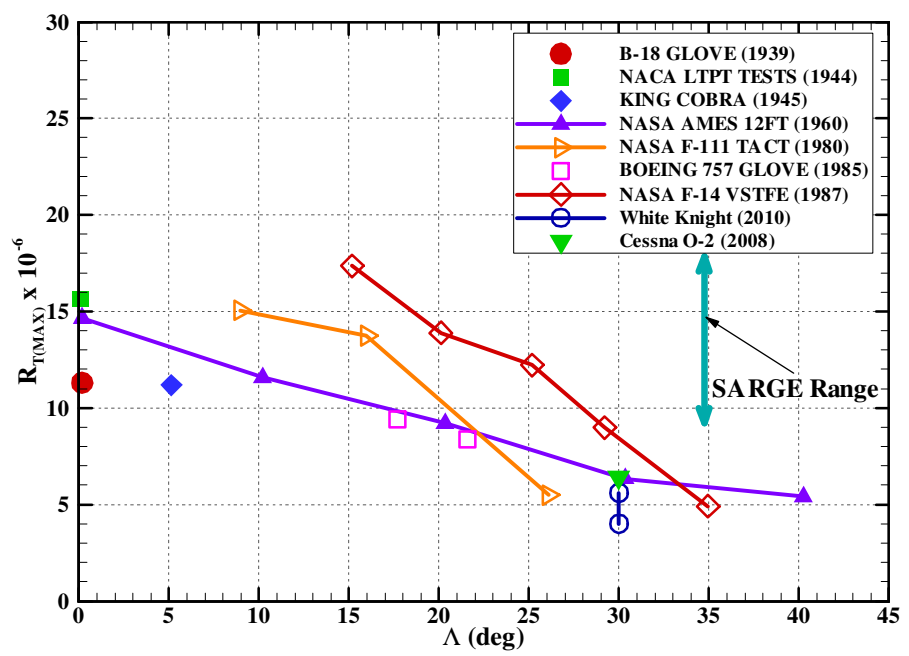

Figure 2. Maximum transition Reynolds numbers as a function of wing sweep for various NLF experiments. 


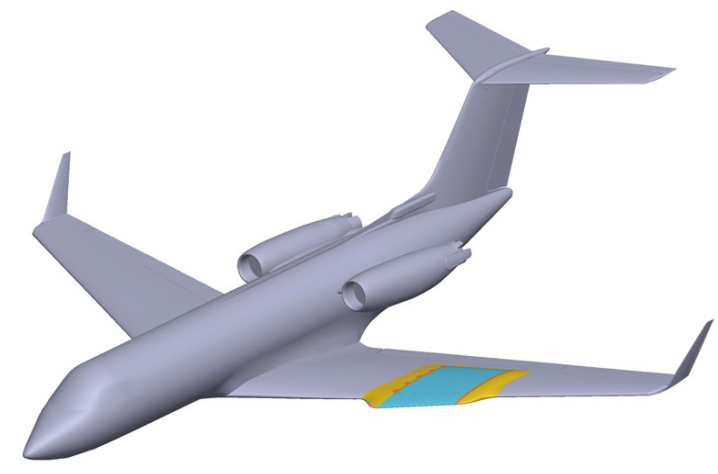

(a)

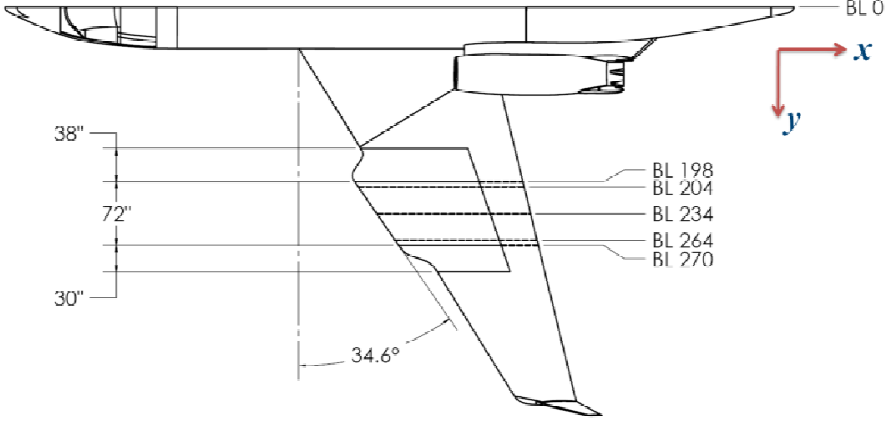

(b)

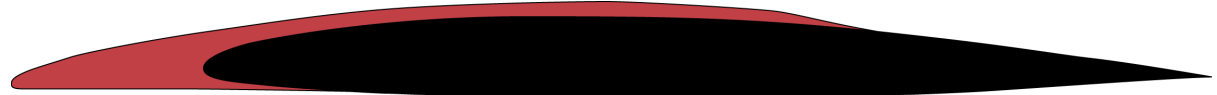

(c)

Figure 3. Gulfstream-III (G-3) aircraft and the glove. (a) Glove as installed on the G-3 wing, (b) Planform showing glove dimensions and fairings, (c) Cross-section of wing-glove.

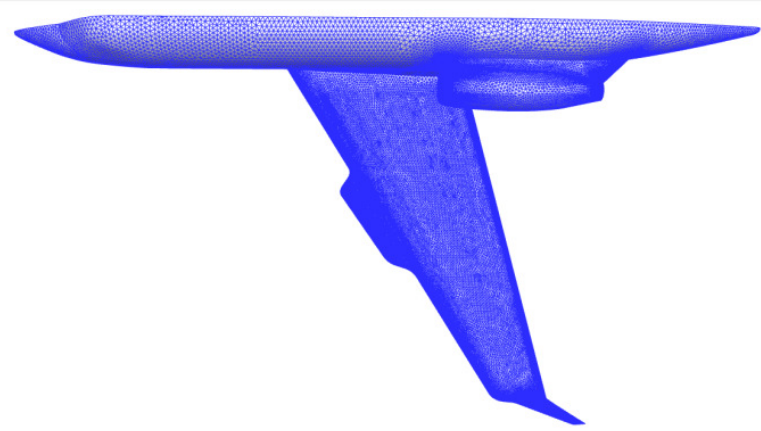

(a)

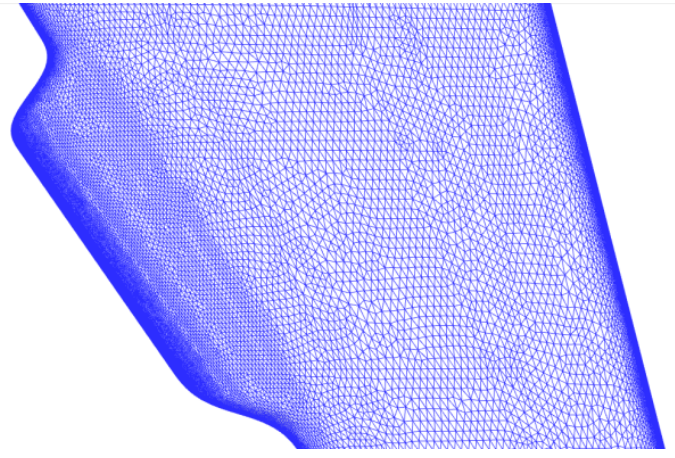

(b)

Figure 4. Tetrahederal surfacegrid used in the analysis. (a) Grid for the G-3 aircraft, (b) Grid in the glove region. 


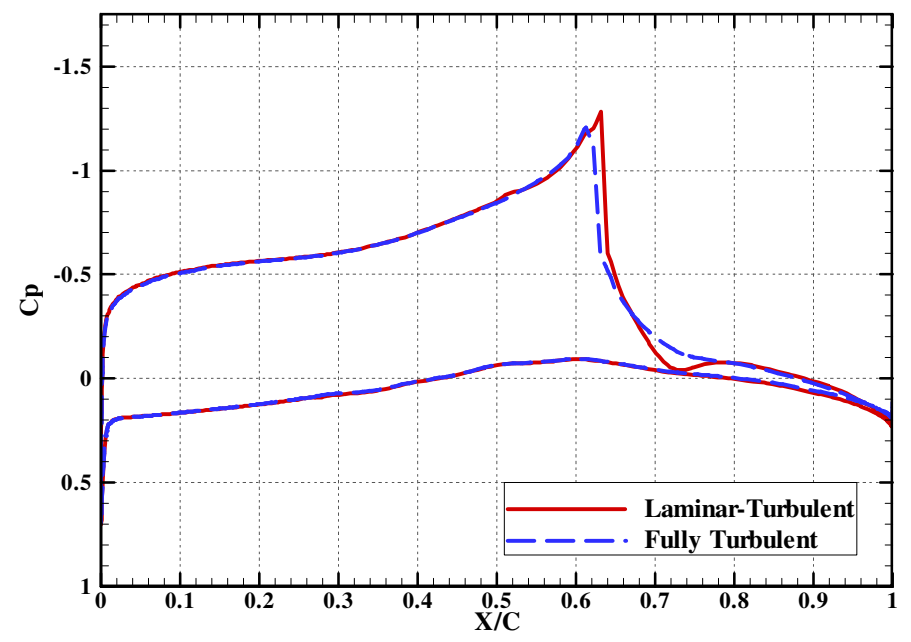

Figure 5. Computed $\mathrm{Cp}$ at the mid-span location $(\mathrm{y}=234$ ") assuming turbulent flow everywhere and turbulent flow with laminar on the glove.

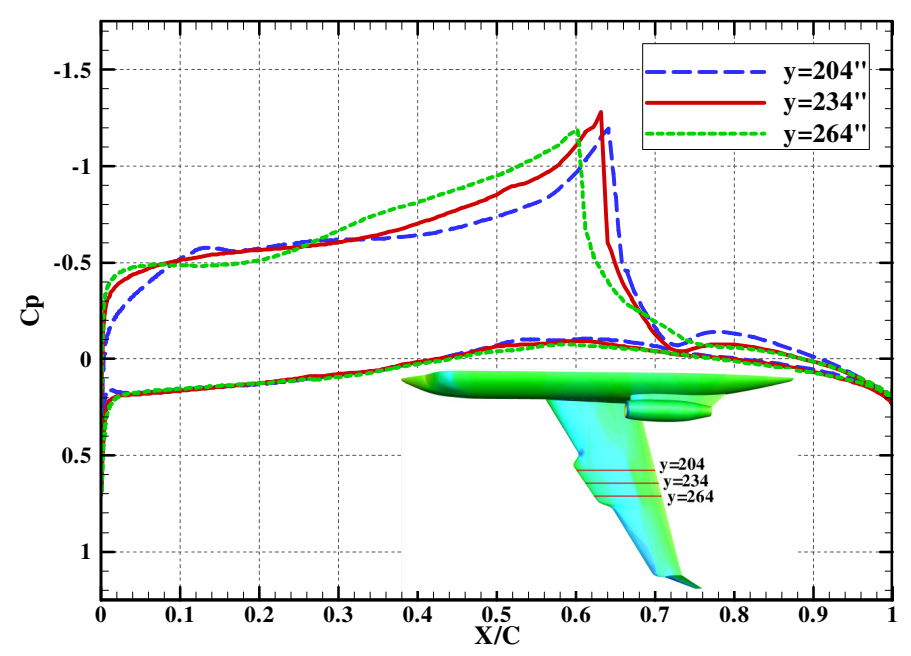

Figure 6. Comparison of Cp distributions at three spanwise stations on the glove, y =204", 234", and 264". 


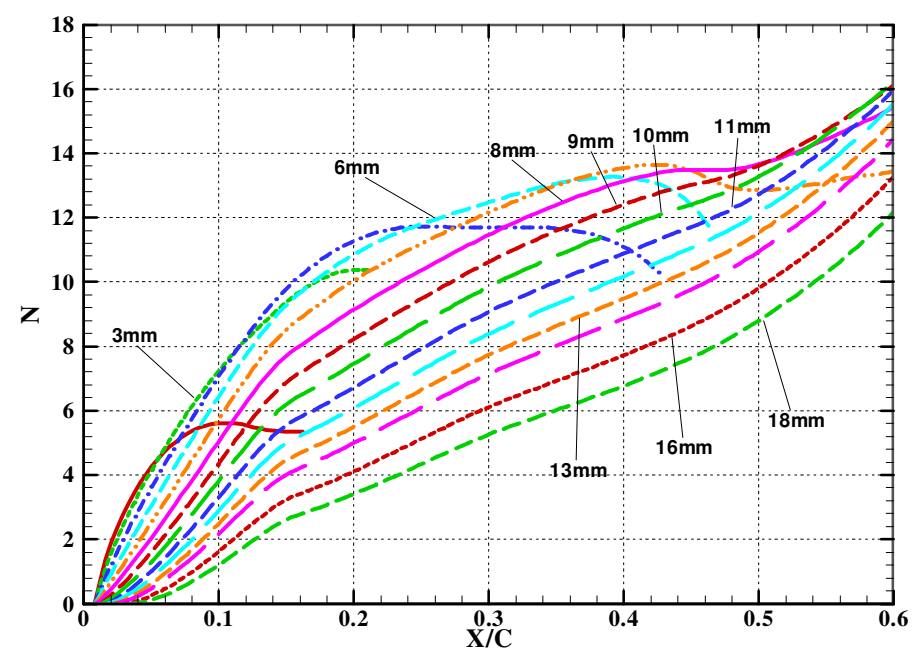

(a) $\mathrm{y}=204 "$

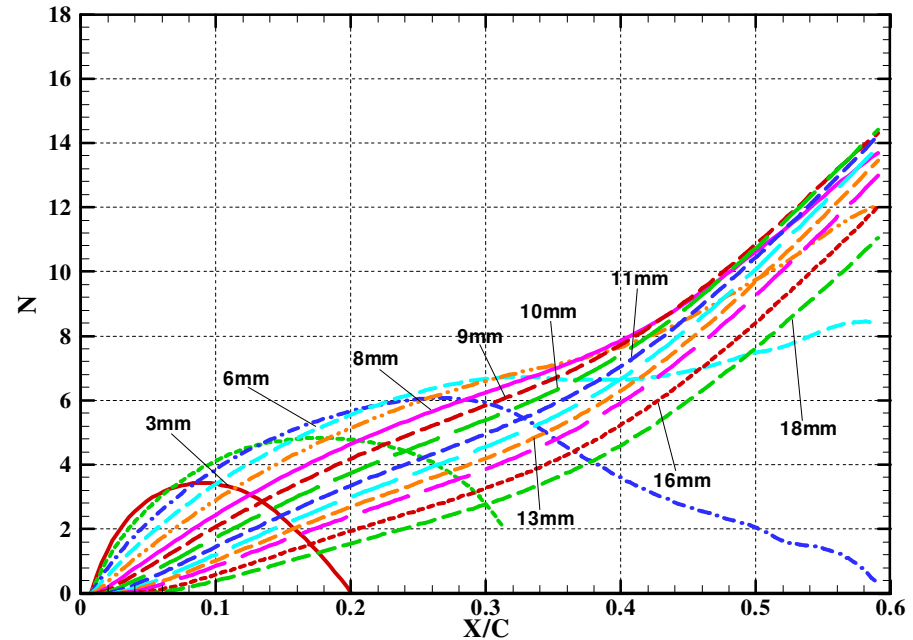

(b) $\mathrm{y}=234 "$

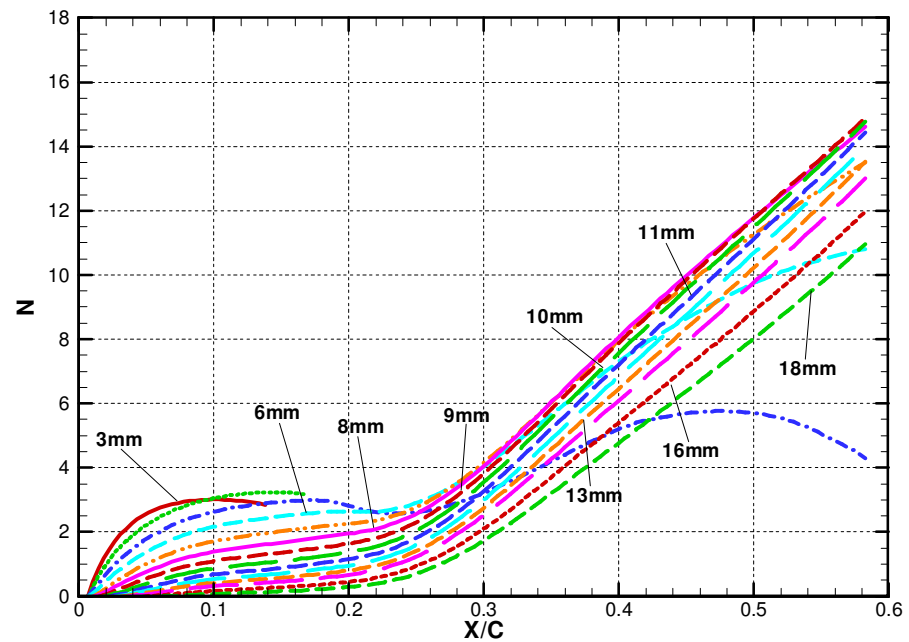

(c) $\mathrm{y}=264 "$

Figure 7. Stationary crossflow N factors computed using LST for several disturbance wavelengths. 


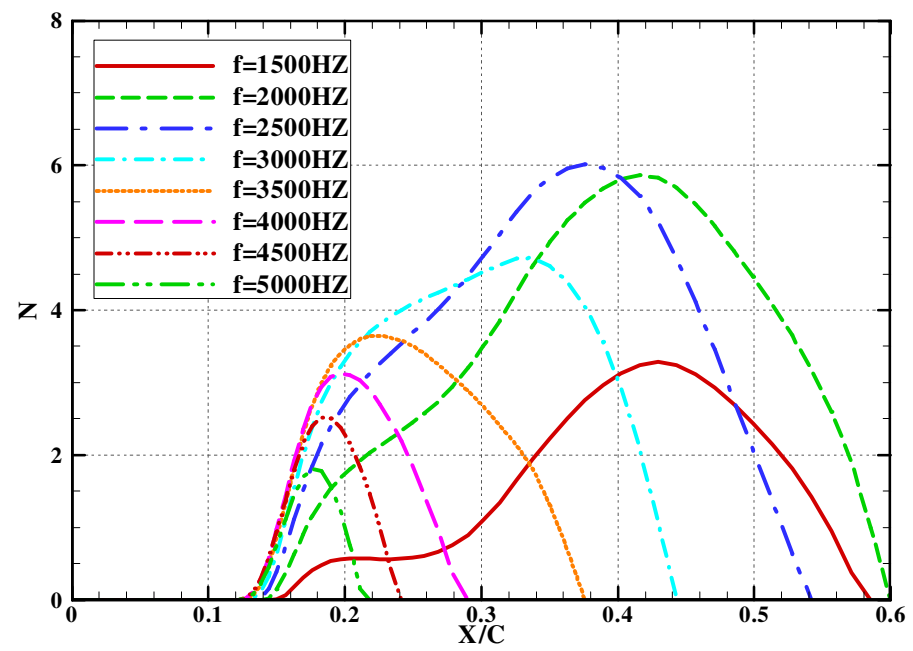

(a) $\mathrm{y}=204 "$

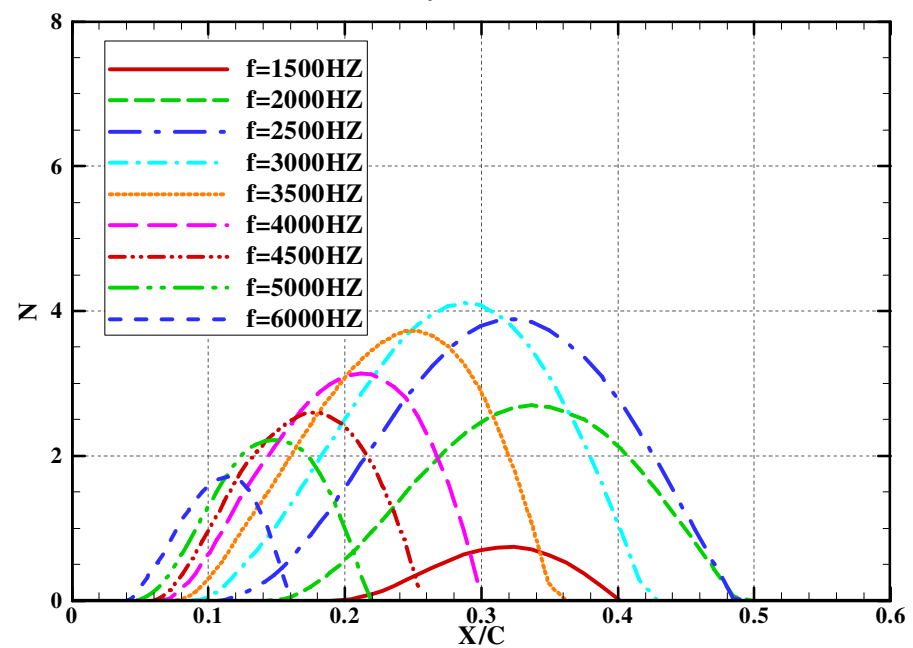

(b) $\mathrm{y}=234 "$

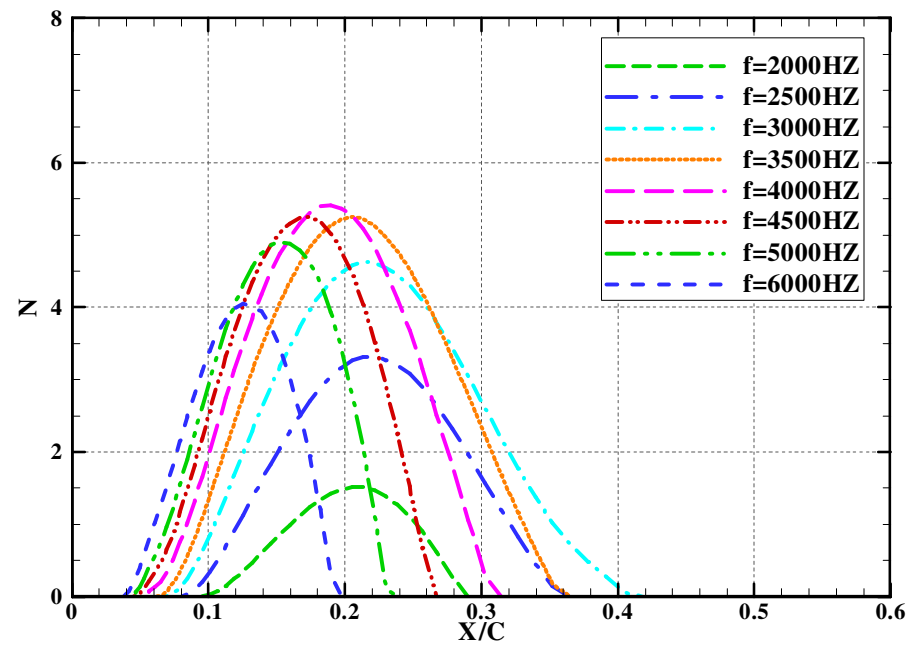

(c) $\mathrm{y}=264 "$

Figure 8. LST N-factor results for TS waves computed for fixed wave angle $(\psi)$ of $0^{\circ}$ with respect to inviscid streamlines. 


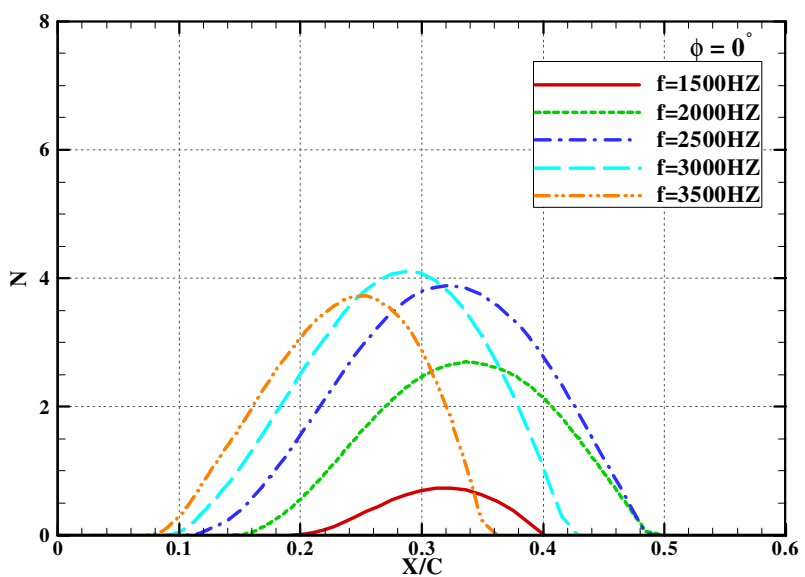

(b)

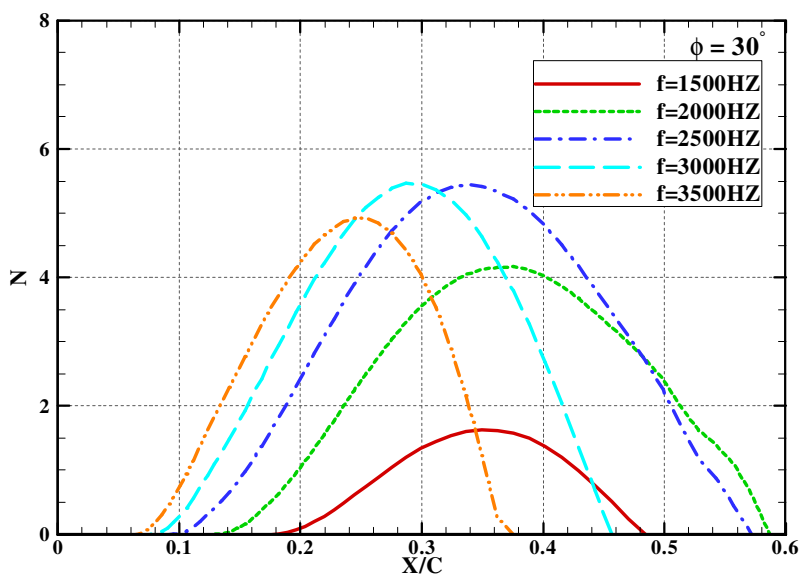

(c)

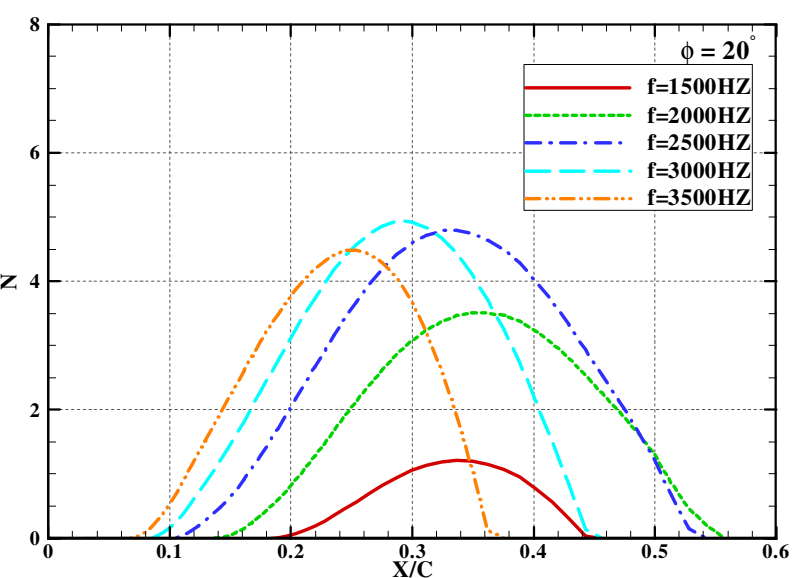

(b)

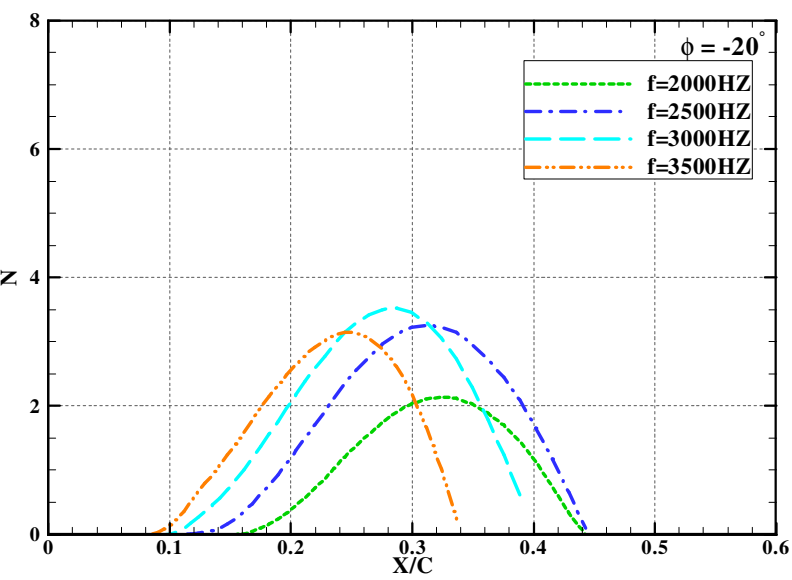

(d)

Figure 9. Effect of wave angles on TS N factors: (a) $\psi=0^{\circ}$, (b) $\psi=20^{\circ}$, (c) $\psi=30^{\circ}$, (d) $\psi=-20^{\circ}$.

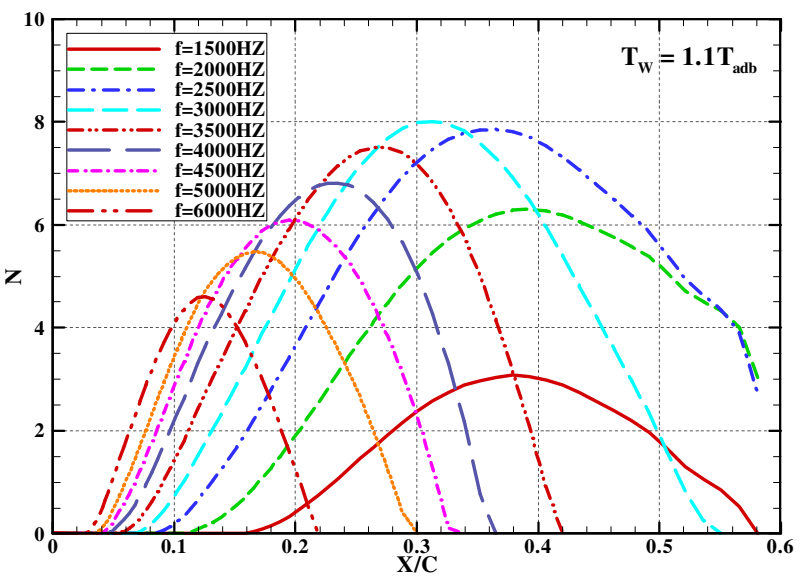

Figure 10. $\mathrm{TS} \mathrm{N}$ factors with $\mathrm{T}_{\mathrm{w}}=1.1 \mathrm{~T}_{\mathrm{adb}}$ and $\psi=30^{\circ}$ (compare with Fig. 9 (c)).

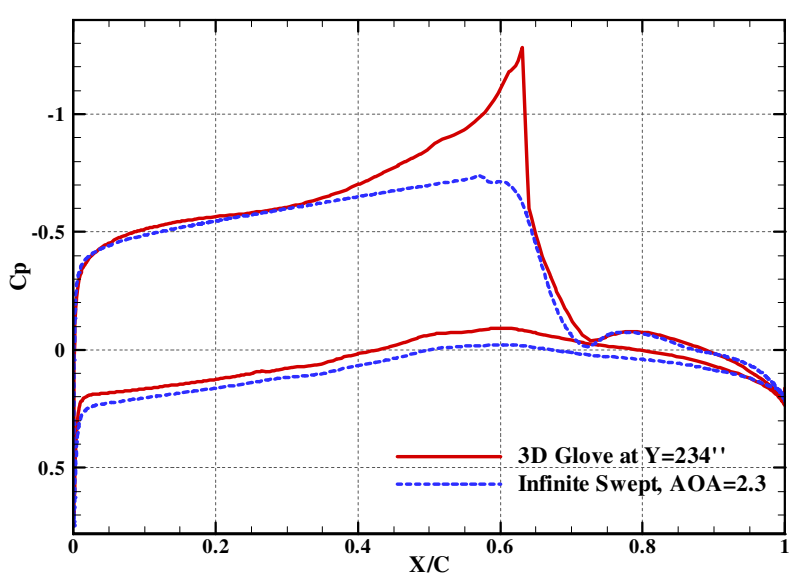

Figure 11. Comparison of $\mathrm{Cp}$ for the mid-span station of 3D glove with that of the infinite-swept airfoil (target $\mathrm{Cp}$ ). 


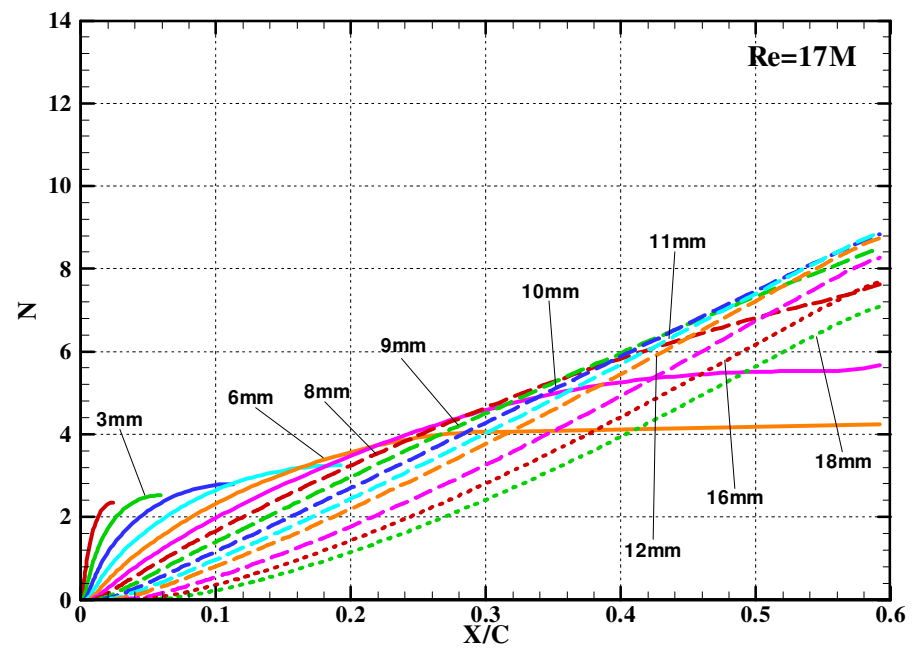

(a) $\operatorname{Re}_{\mathrm{c}}=17 \times 10^{6}$

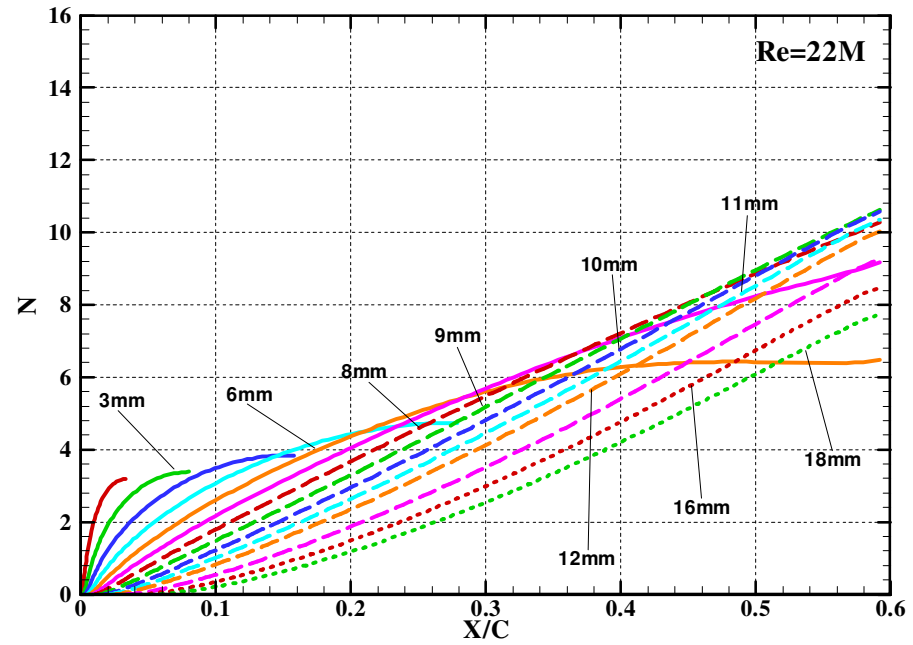

(b) $\operatorname{Re}_{\mathrm{c}}=22 \times 10^{6}$

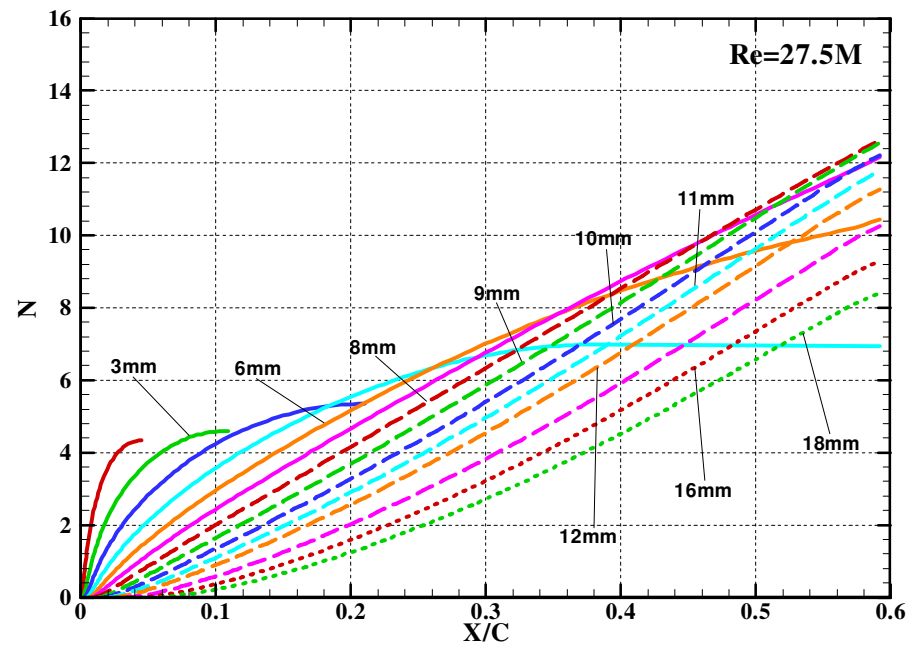

(c) $\operatorname{Re}_{c}=27.5 \times 10^{6}$

Figure 12. LST crossflow $\mathrm{N}$ factors for the infinite-swept airfoil. 


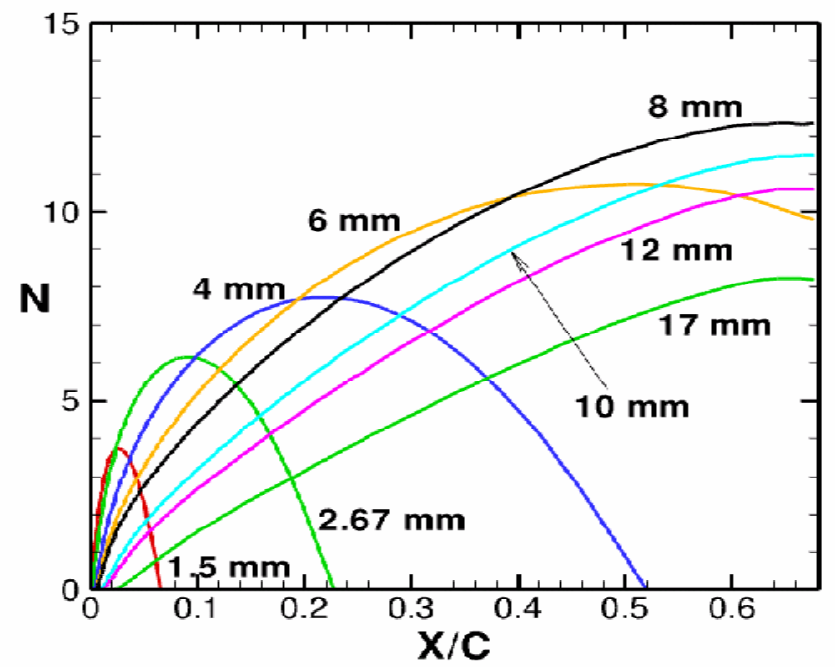

Figure 13. PSE N factor results for the G-2 airfoil, $\operatorname{Re}_{\mathrm{c}}=17 \times 10^{6}$ (from Ref. 45)

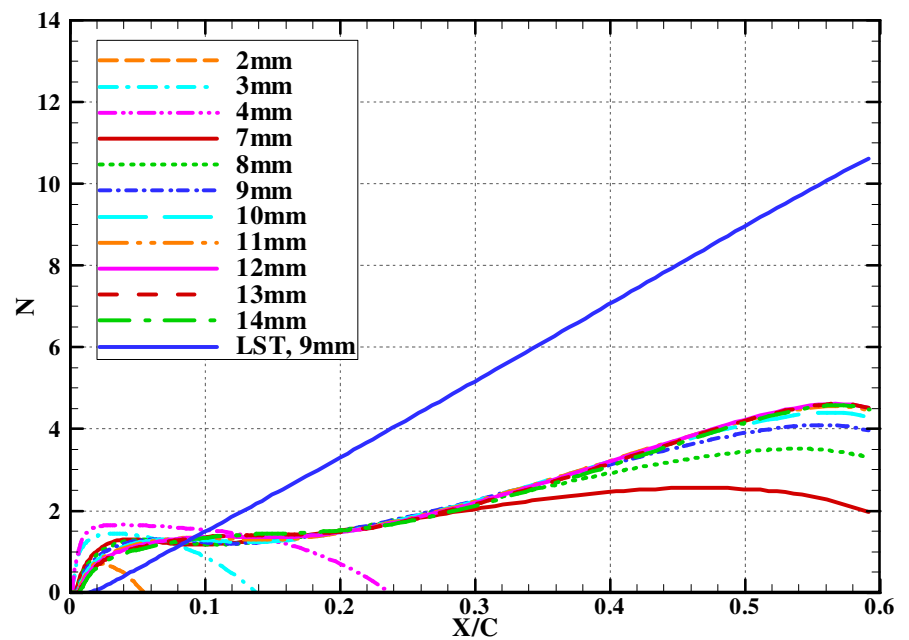

Figure 14. PSE N factor results for the G-3 airfoil, $\operatorname{Re}_{\mathrm{c}}=22 \times 10^{6}$ (LST result for the most amplified wavelength shown for comparison).

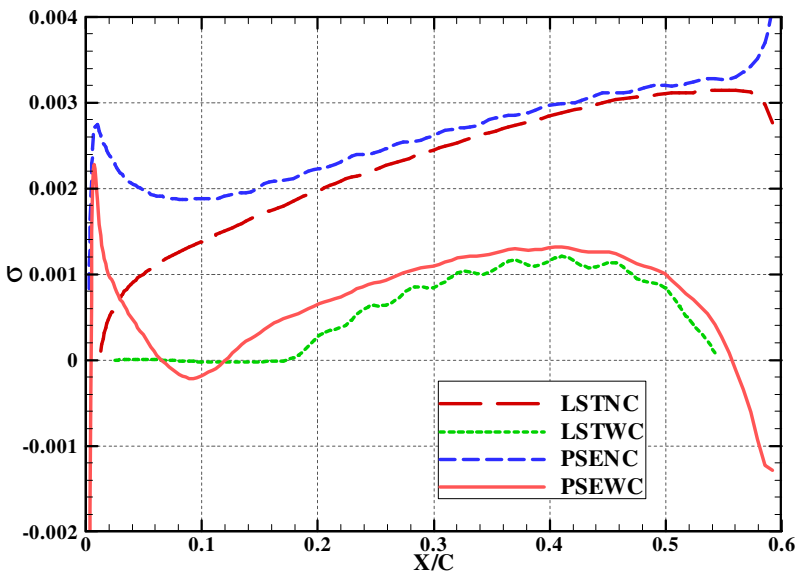

(a)

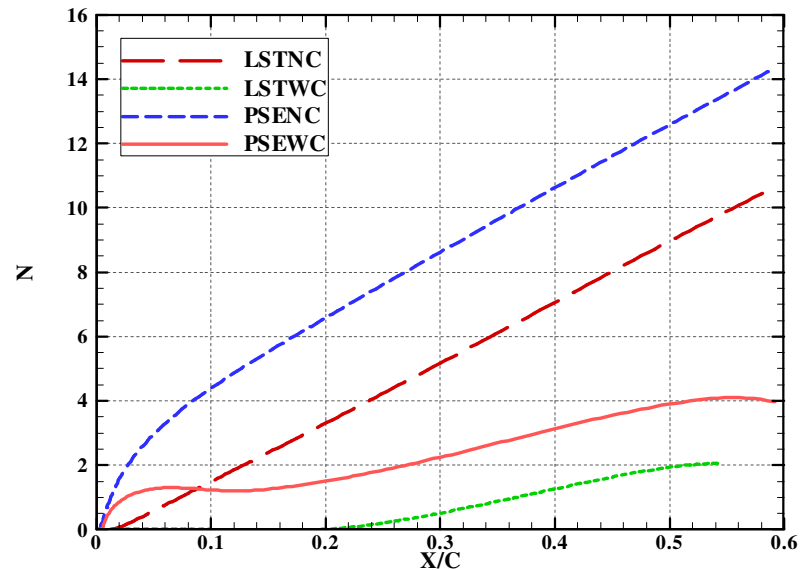

(b)

Figure 15. Nonparallel and surface curvature effects on disturbance growth rate and $\mathrm{N}$ factor with $\lambda=9 \mathrm{~mm}$ for G-3 airfoil, $\operatorname{Re}_{\mathrm{c}}=22 \times 10^{6}$. (a) Growth rate, (b) $\mathrm{N}$ factor. 


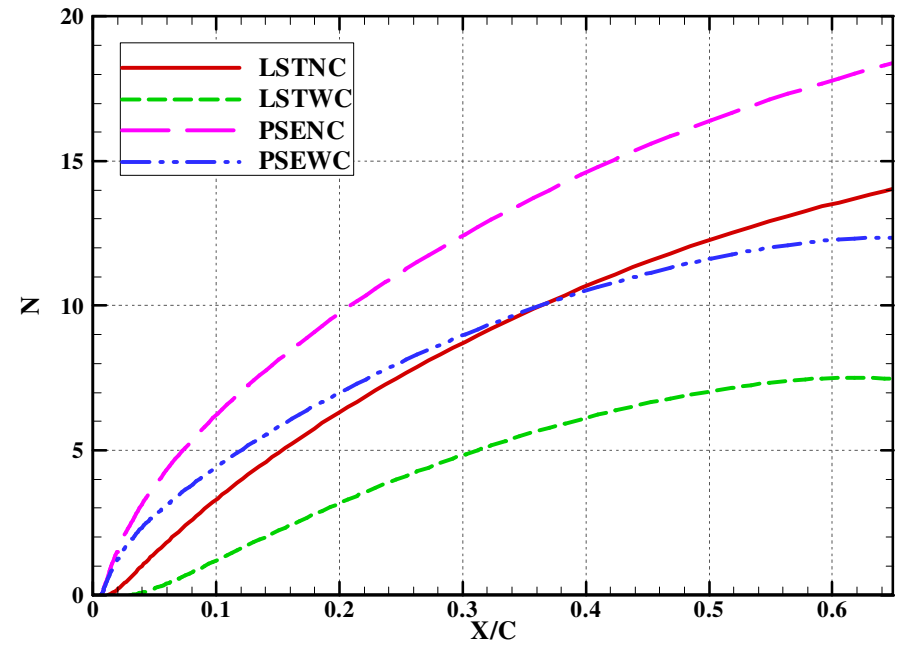

Figure 16. Nonparallel and surface curvature effects on $\mathrm{N}$ factors for the G-2 airfoil, $\operatorname{Re}_{\mathrm{c}}=17 \times 10^{6}$.

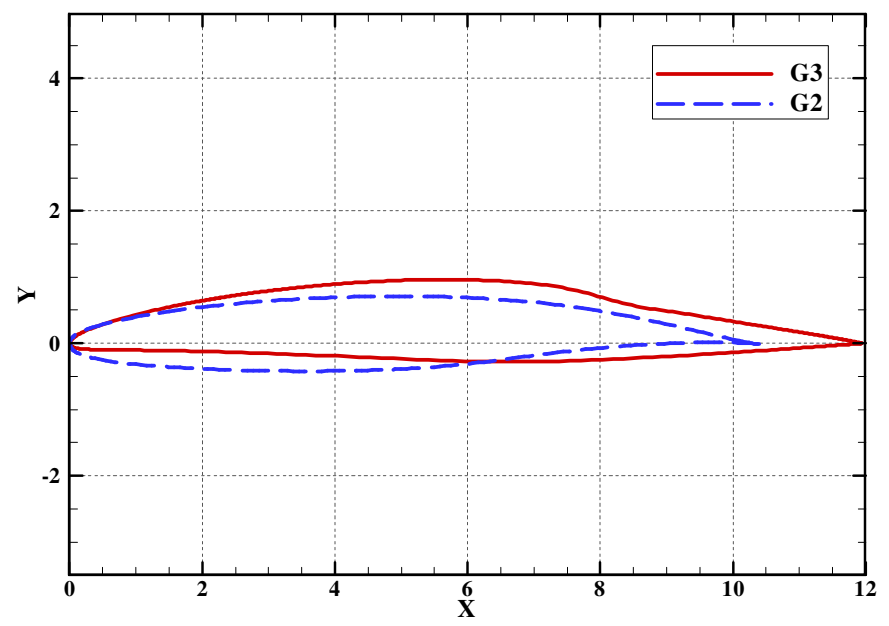

(b)

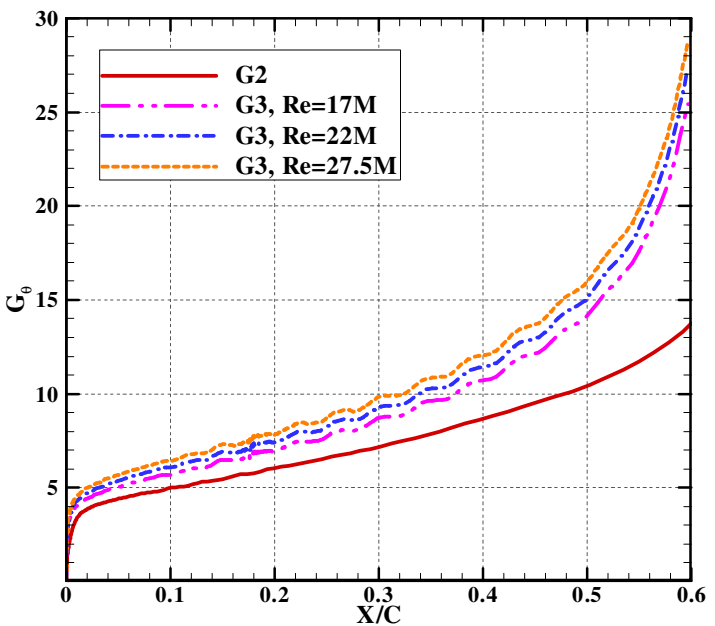

(b)

Figure 17. Comparison of G-2 and G-3 airfoils: (a) chordwise geometry, (b) Gortler number. 


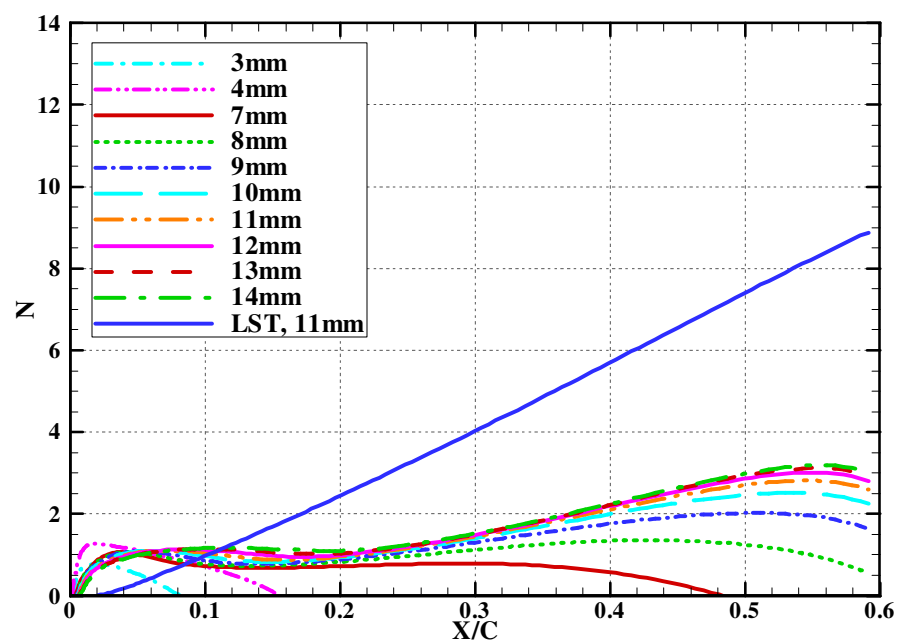

(a) $\mathrm{Re}_{\mathrm{c}}=17 \times 10^{6}$

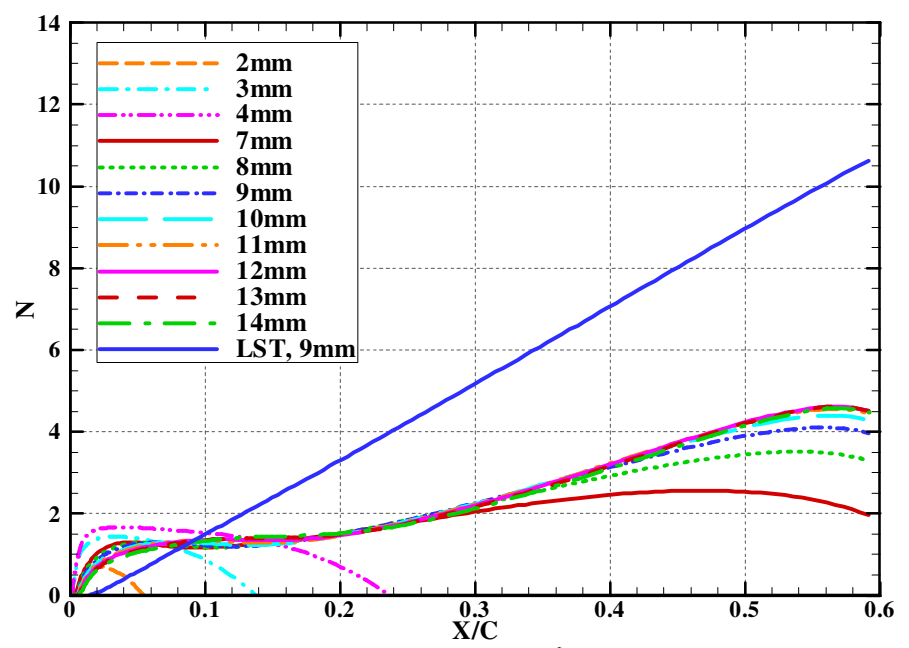

(b) $\operatorname{Re}_{\mathrm{c}}=22 \times 10^{6}$

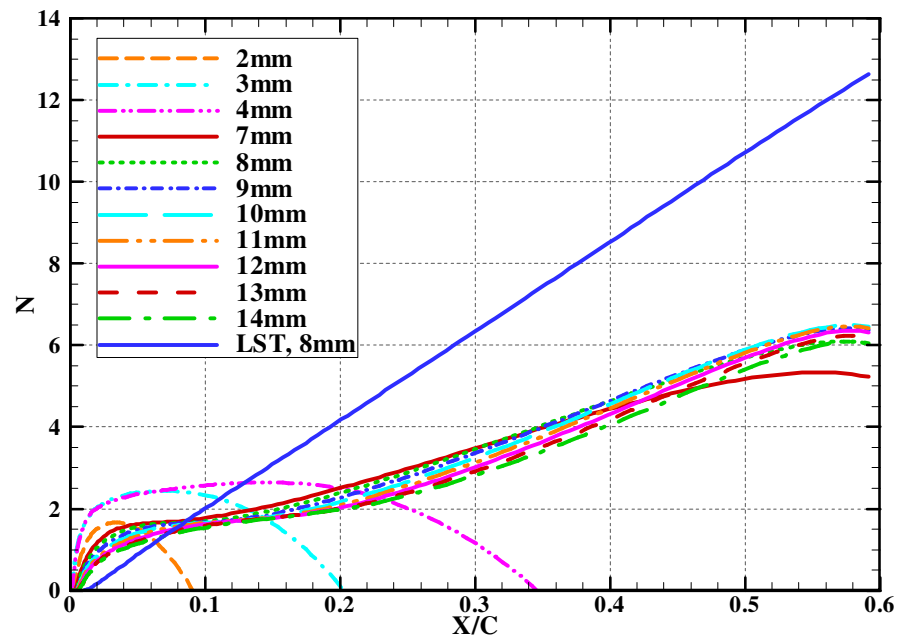

(c) $\operatorname{Re}_{\mathrm{c}}=27.5 \times 10^{6}$

Figure 18. PSE N-factor results for the three Reynolds numbers (for reference, LST results for most amplified wave length are also shown). 


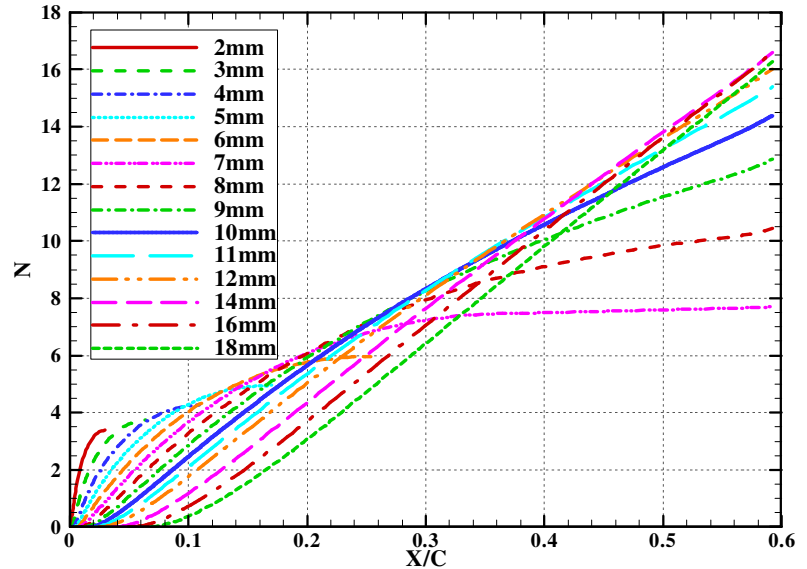

(a)

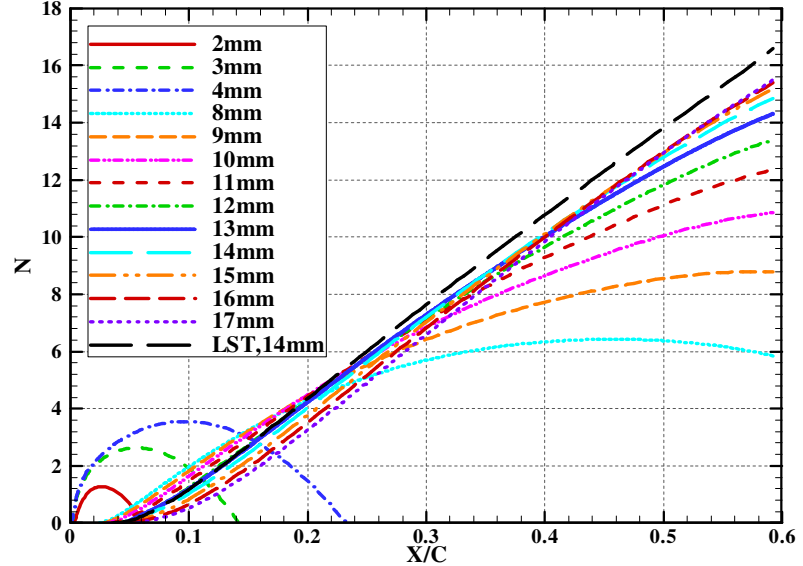

(b)

Figure 19. $\mathrm{N}$ factors for traveling instability waves $(f=1,000 \mathrm{~Hz})$ of different spanwise wavelengths. (a) LST, (b) PSE.

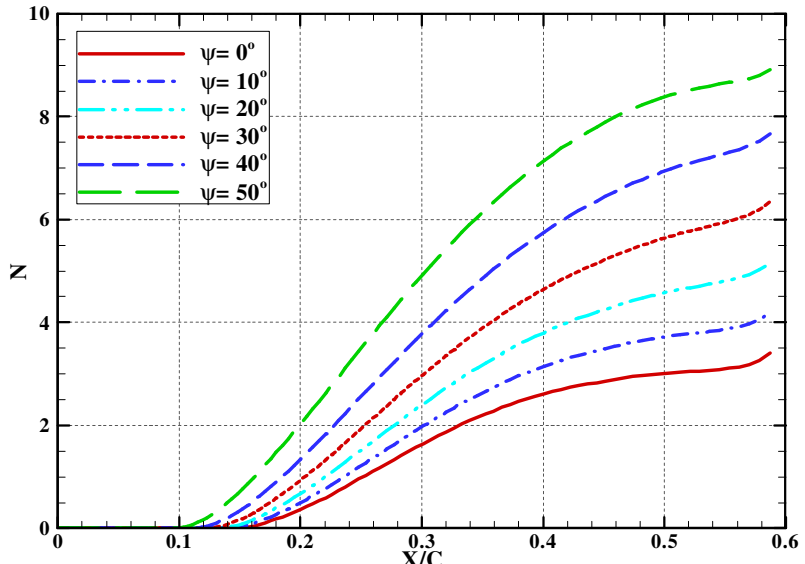

(a)

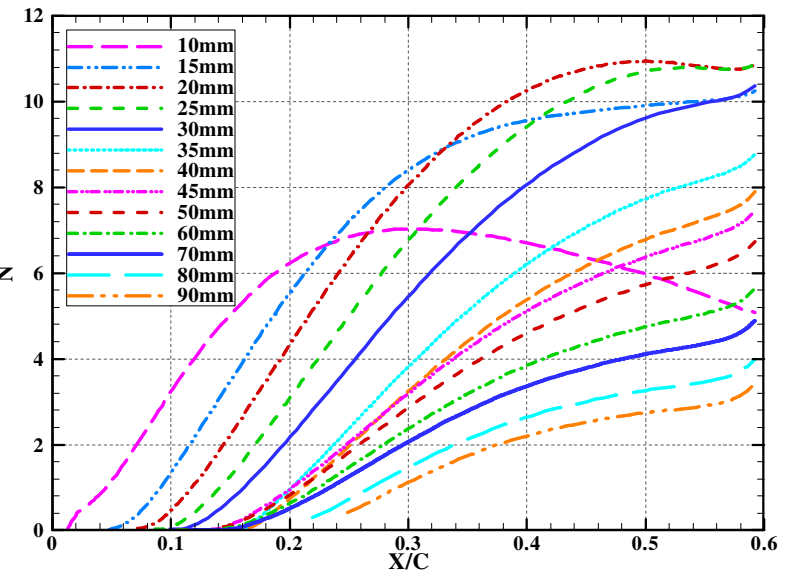

(b)

Figure 20. $\mathrm{N}$ factors for a disturbance frequency of 2,000HZ. (a) LST for different wave angles, (b) PSE for different spanwise wavelengths.
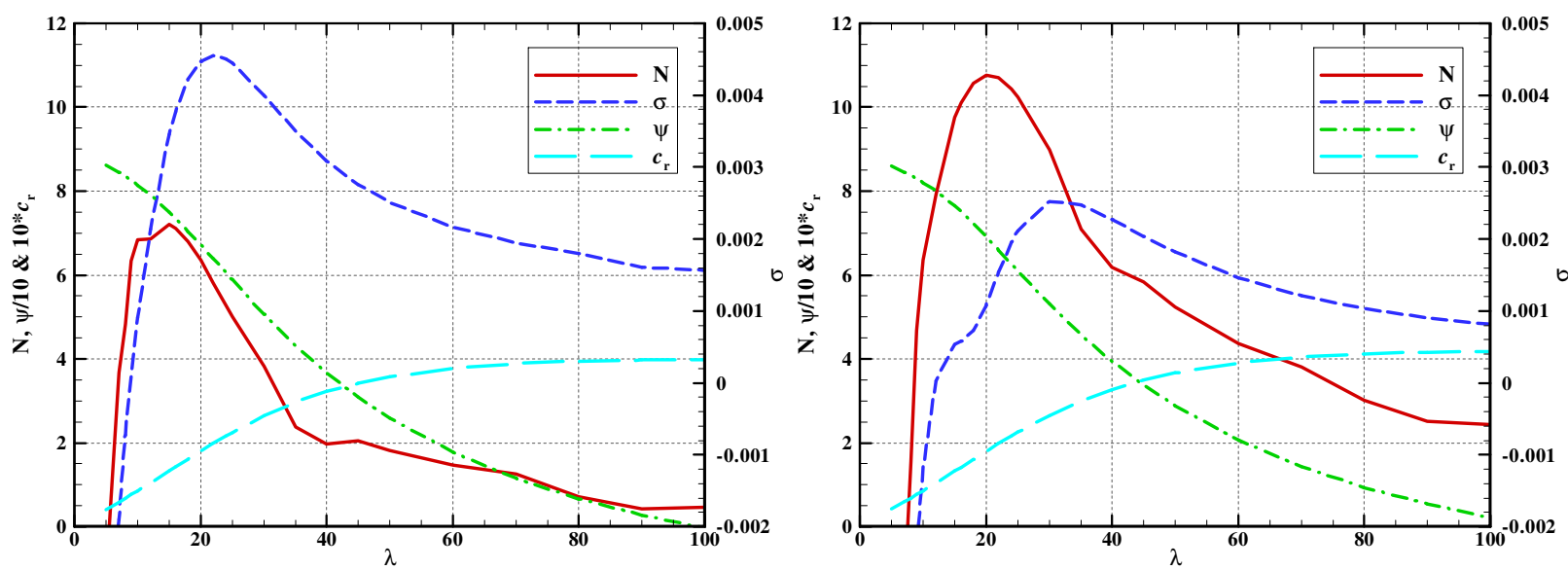

Figure 21. PSE growth rate $(\sigma), \mathrm{N}$ factors $(\mathrm{N})$, wave angles $(\psi)$, and phase speed $\left(c_{\mathrm{r}}\right) v s$. spanwise wavelengths $(\lambda)$ for a disturbance frequency of 2,000HZ. (a) $x / c=0.25$, (b) $x / c=0.45$. 